\title{
Dollar Illiquidity and Central Bank Swap Arrangements During the Global Financial Crisis
}

\author{
Andrew K. Rose and Mark M. Spiegel*
}

January 19, 2012

\begin{abstract}
While the global financial crisis was centered in the United States, it led to a surprising appreciation in the dollar, suggesting global dollar illiquidity. In response, the Federal Reserve partnered with other central banks to inject dollars into the international financial system. Empirical studies of the success of these efforts have yielded mixed results, in part because their timing is likely to be endogenous. In this paper, we examine the cross-sectional impact of these interventions. Theory consistent with dollar appreciation in the crisis suggests that their impact should be greater for countries that have greater exposure to the United States through trade and financial channels, less transparent holdings of dollar assets, and greater illiquidity difficulties. We examine these predictions for observed cross-sectional changes in CDS spreads, using a new proxy for innovations in perceived changes in sovereign risk based upon Google-search data. We find robust evidence that auctions of dollar assets by foreign central banks disproportionately benefited countries that were more exposed to the United States through either trade linkages or asset exposure. We obtain weaker results for differences in asset transparency or illiquidity. However, several of the important announcements concerning the international swap programs disproportionately benefited countries exhibiting greater asset opaqueness.
\end{abstract}

JEL classification: E44, E58, F31, F33, F41, F42, G15, O24

Key words: illiquidity, dollar, exchange rate, financial crisis, Federal Reserve, swaps, TAF

\footnotetext{
*U.C. Berkeley, Haas School of Business, arose@haas.berkeley.edu, and Federal Reserve Bank of San Francisco, mark.spiegel@sf.frb.org. Christopher Candelaria and Israel Malkin provided excellent research assistance. Helpful comments were received from two anonymous referees, Elena Dumitrescu, Charles Engel, Kristin Forbes, Linda Goldberg, Pierre-Olivier Gourinchas, Galina Hale, Steve Kamin, Qing Liu, Richard Portes, Jim Poterba, Vince Reinhart, Bent Sorensen, Jeremy Stein, Beatrice Weder, Randy Wright, Thomas Wu, and seminar participants at the NBER IFM summer institute, the NBER Conference on the Global Financial Crisis, the Bank of England Research Forum on Unconventional Monetary Policy, the Federal Reserve Bank of Chicago Summer Money Workshop, the Fourth MIFN Conference, Shandong University, Tsinghua University, and U.C. Santa Cruz. Key data and output are available at http://faculty.haas.berkeley.edu/arose. A technical appendix providing detailed proofs of the material in the appendix is http://www.frbsf.org/economics/economists/mspiegel/wp11-18appendix.pdf. All views presented in this paper are those of authors and do not represent the views of the Federal Reserve Bank of San Francisco or Federal Reserve System.
} 


\section{Introduction}

The recent global financial crisis originated and was centered in the United States. When difficulties arose in sub-prime mortgages in early 2007, investors became concerned about a wide set of U.S. assets, resulting in fire sales and the failure or near-failure of a number of systemically important U.S. financial firms [Bernanke (2009)]. Between October 2007 and October 2008, there was a $\$ 8$ trillion sell off in U.S. equity values [Brunnermeier (2009)]. A surprising feature of the recent financial crisis is that at its peak the American dollar actually rose in value. Going into the crisis, most thought that the adjustment process to undo the large global imbalances that had built up during the boom would include a sharp dollar depreciation [e.g. Krugman (2007)].

Instead, the crisis country currency appreciated [Engel (2009)]. For example, see Figure 1, which plots the VIX and VSTOXX measures of US and European equity market volatility respectively against the dollar-euro exchange rate during late 2008. The dollar exchange rate moved quite closely with volatility in equity markets, as can be seen by examining plots of the VIX and VSTOXX indices. This leads us to the view that the appreciation of the dollar resulted from a flight to liquidity rather than solely a flight to safety.

While there probably was some movement towards safety [e.g. Fratzscher (2009), McCauley and McGuire (2009)], we concentrate on the liquidity issue here. Many studies [e.g. Baba and Packer (2009b)] characterize the illiquidity as a shortage in dollar funding suffered by financial institutions. Viewed from the prism of a global dollar liquidity shortage due to the unique role played by the dollar in global financial markets, the temporary appreciation of the dollar is unsurprising 1

At the height of the crisis, the Federal Reserve extended dollar assets to major industrial

\footnotetext{
${ }^{1}$ Goldberg and Tille (2008) show that the dollar plays a prominent role in invoicing in international transactions, even in many that do not involve agents from the United States. Similar concerns drive currency invoicing decisions in debt issuance [Chinn and Frankel (2007)]. The impact of scale effects has been demonstrated in the case of the advent of the euro, where the increased volume of existing issuance in euro relative to national currencies resulted in a substantial move towards the euro in new issuance [Hale and Spiegel (2008)].
} 
countries, and several emerging markets' central banks to alleviate these dollar shortages $2^{2}$ Obstfeld, Shambaugh, and Taylor (2009) note that desirable alternatives to the swap arrangements did not exist, as increased domestic currency extensions from local central banks could have led to undesirable currency depreciation, and the use of foreign central bank dollar reserves would have reduced their holdings, raising anxiety $\left.\right|^{3}$ They argue that the broad injection of dollar liquidity was "... one of the most notable examples of central bank cooperation in history ..."

The swaps were short-term arrangements, never exceeding 30 days, and were thus unlikely to affect default risk. Rather, they were explicitly intended to address liquidity problems. Indeed, the first FAQ on the Federal Reserve web page [Federal Reserve (2011)], answers the question "What was the purpose of the dollar liquidity swap lines?" with "The dollar liquidity swap lines were designed to improve liquidity conditions in U.S. and foreign financial markets by providing foreign central banks with the capacity to deliver U.S. dollar funding to institutions in their jurisdictions during times of market stress."

The evidence on the impact of central bank interventions is mixed. Some of the studies [e.g. Taylor and Williams (2009)] find no impact, while others, such as McAndrews, Sarkar, and Wang (2008), find significant but small impacts. More recent studies, such as Baba and Packer (2009b), concentrate on the most turbulent portion of the crisis and find larger effects. However, the endogeneity of these injections, which were provided when and where they were most needed, poses a challenge in evaluating their impact.

Given these difficulties, we examine the cross-sectional impacts of central bank efforts to address dollar-funding shortages. We begin with a descriptive overview of the central bank responses to the global financial crisis, reviewing a number of the relevant empirical regularities that have been found in the literature. We then discuss the implications of a theoretical model derived in a

\footnotetext{
${ }^{2}$ Some have also suggested that the swaps were motivated by a desire to mitigate the aforementioned exchange rate pressures.

${ }^{3}$ Some emerging market country swap arrangements reflected their desire to avoid obtaining funds from the International Monetary Fund, and may have more reflected the need for hard currency reserves [e.g. Engel (2009)].
} 
companion paper [Rose and Spiegel (2011)] - and summarized in the appendix - that describes the crisis as stemming from toxic American assets but still predicts the observed dollar appreciation.

We then bring the cross-sectional predictions of that model to the data to reassess the impact of the attempts by the Federal Reserve and others to inject dollar liquidity into the global financial system. Theory suggests that the impact of these injections should be greater among countries that have greater exposure to the United States through trade and financial channels, less transparent holdings of dollar assets, and greater illiquidity difficulties. We test these hypotheses by examining the impact of announced U.S. dollar auctions by foreign central banks, weighted by the size and average maturity of auctioned assets, on CDS spreads for a large cross-section of countries. We find robust evidence that the auctions disproportionately benefited countries that were more exposed to the United States, either through trade or financial channels, as the theory predicts. We obtain weaker or incorrect results for national differences in the impact of the auctions by the transparency of their dollar holdings and measures of illiquidity.

We also examine the impacts of the major announcements concerning the international swap arrangements. For several of the most important announcements, such as the one that removed the ceilings on swaps with major foreign central bank partners and the announcement initiating swap arrangements with a broader set of countries, our results for announcements roughly match those for the actual auctions. However, for others, such as the actual launch of the program, we find disproportionate benefits among countries exhibiting greater illiquidity.

The following section reviews the evidence in the literature on the impact of the central bank swap lines on global financial conditions. Section 3 discusses our base empirical specification. Section 4 subjects our results to a battery of robustness tests. Lastly, section 5 concludes. 


\section{Evidence on the impact of the swap arrangements}

Major announcements concerning international swap lines by the Federal Reserve during this period are shown in Table 1. The first is December 12, 2007, when the Federal Reserve announced its swap arrangements with the European Central Bank (ECB) and the Swiss National Bank (SNB). These were initially capped at $\$ 20$ and $\$ 4$ billion respectively. With the increased turmoil in global financial markets in the fall of 2008, swap lines were extended and expanded. On September 18, 2008, lines were introduced for the Bank of England (BOE), the Bank of Japan (BOJ) and the Bank of Canada, while lines with the ECB and the SNB were increased. Less than a week later, on September 24, swap facilities were introduced for the Reserve Bank of Australia, the Swedish Riksbank, the Denmark National Bank, and the Norwegian Central Bank. In October of the same year, existing lines were "uncapped," on October 13 for the BOE, the ECB and the SNB, and on October 14 for the BOJ. Finally, on October 28, 2008, lines were introduced for New Zealand, and on October 29, for Brazil, Mexico, Korea, and Singapore 4 The range of swap lines was also broadened over this period from longer-term offers (one to three months) to also include one week and overnight offers, and from primarily repos and collateralized loans to also include foreign exchange swaps [Ho and Michaud (2008)]. Other nations, including the Swiss National Bank and the ECB, also entered into swap arrangements with other countries with funding needs in those countries' currencies.

These swap lines allowed these foreign central banks to access dollar-denominated assets which they could then lend to their financial institutions that were experiencing dollar illiquidity. These loans provided dollar funds to institutions in the European Union with ECB-eligible collateral [Baba and Packer (2009a)]. At the height of the program at the end of 2008, draw downs reached $\$ 291$ billion at the ECB, $\$ 122$ billion at the BOJ, and $\$ 45$ billion at the Bank of England [Goldberg,

\footnotetext{
${ }^{4}$ See Ho and Michaud (2008) and Goldberg, Kennedy, and Miu (2010) for reviews of the details of the central bank swap programs during the crisis.
} 
Kennedy, and Miu (2010)].

Other efforts were also initiated. The term auction facility (TAF) program, aimed at providing funds to financial institutions, was introduced in December of 2007. Through this facility, depository institutions were able to borrow directly from the Federal Reserve without using the discount window [Taylor and Williams (2009)] $\mathrm{f}^{5}$ The ECB also conducted dollar term funding auctions.

The volume of TAF auctions increased dramatically during the fall of 2008 , coinciding with the dates of the Lehman failure and the subsequent market turmoil. As financial conditions improved, however, the terms offered under the overseas swap facilities became less desirable. Offer rates for dollar swap facility funds reached about 100 basis points higher than terms available to US and some foreign financial institutions under the TAF program. Moreover, by the first quarter of 2009 the market terms had improved to the point that participation in central bank swaps would only have been attractive to institutions lacking access to funds in private markets or lacking collateral necessary to participate in the TAF program [Goldberg, Kennedy, and Miu (2010)]. The volume of draw-downs decreased quickly as conditions improved (See Figure 2).

The swap arrangements were a crucial part of efforts by global officials to restore liquidity to the financial system, as evidenced by the enormous draw downs at the end of 2008. Table 2 reports the volume and average tenor of the TAF funds auctioned by the four major central banks over the course of our sample. It is clear that this injection of dollar-denominated capital was large, with volumes peaking in the fall of 2008 for the four major foreign central banks 6

A number of studies have emerged attempting to gauge the success of the programs in improving global dollar liquidity. In an early study, Taylor and Williams (2009) examine the impact

\footnotetext{
${ }^{5}$ As [Taylor and Williams (2009)] point out, it is important to remember that the liquidity effects of the TAF auctions are not due to any increase in total bank reserves of the amount of "high-powered money" in the financial system, as bank borrowing was offset by open market sales of securities.

${ }^{6}$ The popularity of the swap arrangements imply some market failure in international financial markets, particularly among the major central banks who under normal circumstances would likely be able to raise adequate funds on their own. However, central banks may have been resistant to exacerbate the lack of liquidity in these markets by borrowing in them directly.
} 
of the TAF auctions. They find no impact of these auctions on the 3-month spread of unsecured LIBOR lending rates over overnight index swaps (OIS), which they take as a proxy for interest rate expectations. Their work was followed by a number of researchers, including McAndrews, Sarkar, and Wang (2008), who argued that a proper assessment of the impact of the TAF auctions required looking only at changes in the LIBOR-OIS spreads on days of announcements and auction operations. Using this methodology, they find that the TAF auctions and announcements accounted a cumulative reduction of more than 50 basis points in the OIS-LIBOR spread. Moreover, they find that international TAF auctions also had a statistically significant and even larger impact on spreads than domestic auctions. Both McAndrews, Sarkar, and Wang (2008) and subsequent work by Taylor and Williams (2008) based on spreads find that announcements had larger impacts than actual auctions.

Other efforts to characterize the impact of the central bank dollar injections concentrate on evidence from the FX swap market. As discussed in Baba and Packer (2009b), disruptions in the FX swap market began appearing at the height of the financial crisis. FX swap prices began to reflect increases in perceived counter-party risk among European financial institutions, as doubts grew about the abilities of these institutions to fulfill their dollar obligations. This resulted in deviations from short-term covered interest parity. Baba and Packer (2009b) find that the establishment of the international fund lines, as well as the dollar term funding auctions financed by these swaps, had a significant downward impact on observed deviations from covered interest parity in the FX swap market. They obtain mixed results, as US dollar auctions are found to have had a robust negative impact on deviations to covered interest parity subsequent to the Lehman failure, but not before. Similar results are reported in Baba and Packer (2009a) and Hui, Genberg, and Chung (2010).

The impact of the central bank actions on a broader set of countries is examined by Aizenman and Pasricha (2010). They concentrate on emerging market economies that were granted swap 
arrangements by the Federal Reserve at the height of the crisis. They demonstrate that the set of emerging market economies that received swap arrangements were selected in part on the basis of having exceptionally large outstanding obligations to the Federal Reserve. Their results indicate that the establishment of swap arrangements had little impact on national credit default swap spreads, but did contribute to exchange rate appreciation, or at least stemmed exchange rate depreciation 7

Overall, it is safe to characterize the evidence on the impact of central bank interventions as mixed. Even the work of McAndrews, Sarkar, and Wang (2008), which was subsequently confirmed by Taylor and Williams (2008), only finds about a 2 basis point impact of TAF events on LIBOROIS spreads. While it may not be surprising that the dollar auctions had their greatest effect during the height of the turmoil, it is safe to say that the magnitude of the observed responses during the pre-Lehman period was disappointing. Indeed, it was during this period unprecedented policies were adopted, providing a reminder that while this period was not turbulent relative to what immediately followed, it was still exceptional relative to recent historical data.

A number of difficulties have been pointed out with time series-based evidence. One problem is that these approaches implicitly ascribe all movements not covered by measured changes in counter-party risk to the policy action, while a substantial number of other developments were simultaneously taking place [Taylor and Williams (2009)]. Another is that there is clear evidence that central bank swap policies have been endogenous: Central bank swap partners were clearly not chosen at random. Moreover, Aizenman and Pasricha (2010) find that the set of emerging market economies chosen as candidates for swap arrangements are notable in the magnitude of their outstanding US debt obligations. In addition, the timing of the largest interventions exactly coincides with the period of greatest turmoil. Finally, one would think that private agents would

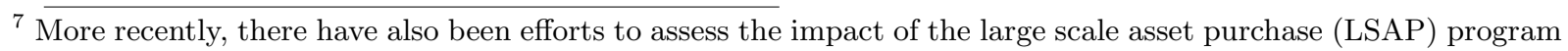
conducted by the Federal Reserve. These studies, including Hamilton and Wu (2012), Krishnamurthy and VissingJorgensen (2011), and D'Amico and King (2011) all find substantial impacts of the LSAP programs had substantial impacts on interest rates.
} 
consider an announcement concerning the design of the international swap program as revealing something about the central banks' views about the severity of the crisis situation. The time series evidence has difficulty separating the direct impact of the program from its impact through private sector expectations $8^{8}$

\section{Empirical specification}

Given the problems discussed in the previous section with existing methodologies, along with the mixed results in the literature, our empirical strategy is to identify cross-sectional restrictions that can be taken to the data to identify the impact of the central bank actions. This approach avoids the timing and endogeneity issues associated with the event-study approaches in the literature. In this section, we first review theoretical underpinnings motivating heterogeneity in the expected impact of the auctions. We then introduce our data set and present basic results.

\subsection{Theoretical motivation}

It seems natural to turn to the literature on money demand based on microeconomic frictions to examine the role of dollar illiquidity in the surprising dollar appreciation during the recent crisis. Early studies, such as Kiyotaki and Wright (1993) and Trejos and Wright (1995) established that a role for money that leads to positive money demand can be motivated within a search model where money acts as a convenient medium of exchange due to its superior liquidity, avoiding the need for a double coincidence of wants. More recently, Lagos and Wright (2005) develop a tractable search-based monetary model by dividing each period into two sub-periods: In the first, agents enter a centralized market in which all goods and assets clear in a very standard manner.

\footnotetext{
${ }^{8}$ One notable exception is D'Amico and King (2011) who identify significant impacts of the LSAP programs in a cross-section of securities. Moreover, they identify effects of pre-announced asset purchases, which they term "flow effects," which are related to the pre-announced injections of dollar liquidity on auction dates that we study below.
} 
However, agents then move on to a decentralized market with anonymous bilateral matching and a double-coincidence problem. The combination of these two markets allows for the incorporation of bargaining under interesting conditions, including the possibility of illiquidity, with tractability ensured by the fact that the next period all agents reunite in the centralized market, where outcomes are degenerate and in particular do not depend on the distribution of money holdings across agents. This methodology was extended further in Lester, Postlewaite, and Wright (2012), who develop a closed-economy model where assets differ in their general acceptability, and hence liquidity. In their model, assets may be of high or low quality, and agents that are uninformed refuse to accept low quality assets in exchange..$^{9}$

In a companion paper [Rose and Spiegel (2011)], whose details are summarized in the appendix of this paper, we develop an international version of the search-based asset model of Lagos and Wright (2005).10 In this model, assets differ in their returns, their "opaqueness," and in their liquidity. The possibility of illiquidity arises because, as in Lester, Postlewaite, and Wright (2012), agents trading in decentralized markets reject opaque assets whose value they don't recognize. We demonstrate that a decline in the yield on the opaque US asset decreases the stock of dollar assets available for transactions purposes, and raises demand for other US assets, such as currency, thereby resulting in an appreciation of the dollar exchange rate. Broadly, we interpret the decline in the yield on the real asset as analogous to the fall in the perceived value of exotic US assets during the global financial crisis, and the appreciation of the dollar relative to the value of the other national currency as analogous to an increase in the relative yield of safe US assets 11

\footnotetext{
${ }^{9}$ See Lester, Postlewaite, and Wright (2011) for a demonstration that equilibria are feasible in which agents reject at any price assets that they do not recognize.

${ }^{10}$ Geromichalos and Simonovska (2011) and Liu (2010) also develop international versions of the Lagos and Wright model. We also include full proofs of the results used in this paper in a technical appendix posted online at http://www.frbsf.org/economics/economists/mspiegel/wp11-18appendix.pdf.

${ }^{11}$ We do not want to suggest that this channel was the only source of dollar illiquidity. Brunnermeier (2009) discusses the "liquidity spirals" that resulted from declines in asset prices that deteriorated bank balance sheet positions, leading to further tightening of lending standards. Emerging market countries also had a need for foreign currency reserves.
} 
This model has implications for the predicted impact of the central bank auctions conducted with dollar funds obtained from the Federal Reserve. We consider the capital injections under the swap program as analogous to an increase in the stock of dollar assets held by agents on entering the market that exhibits dollar illiquidity. In the appendix, we demonstrate that the benefits of this injection are increasing in three characteristics: The first is the probability of needing to transact in US dollars in the decentralized market, which we proxy with alternative measures of exposure, as agents with greater exposure to the United States are more likely to find themselves in need of dollars for transactions or servicing liabilities. The second is the probability of being paired with an uninformed agent, which we interpret as reflected in the "opaqueness" of a country's aggregate dollar holdings. Finally, the impact is predicted to be increasing in the severity of dollar illiquidity in the country ${ }^{12}$

\subsection{Base Specification}

Our base specification examines the cross-sectional restrictions implied by the theory. Initially, we look at an event study specification by examining the average implications of the TAF auctions across the sample, measured by an event dummy corresponding to the week of the auctions, along with interactive slope variables to capture the extra sensitivity exhibited by countries of certain characteristics suggested theoretically. In addition, we include a number of conditioning variables.

For our dependent variable, we follow Aizenman and Pasricha (2010) in using differences in CDS spreads to provide an indicator of liquidity risk. CDS spreads should reflect both default risk and market liquidity. Default risk impacts CDS spreads directly, as they determine the probability of payoffs on these instruments. However, CDS spreads should also reflect market liquidity 13 For

\footnotetext{
${ }^{12}$ Peter and McGuire (2009) also argue that exposure matters, arguing that differences in financial system balance sheet exposure to US assets are likely to be positively correlated with dollar shortage vulnerabilities. While our model literally looks at liquidity shortages in trade, we also consider financial exposure to the United States, such as the exposure measures in Rose and Spiegel (2010).

${ }^{13}$ Hibbert et al (2009, pg. 3) argue that "There is a clear consensus (across an extensive research literature accumulated over more than 30 years) that LP [liquidity premia] do exist across many markets, they can be substantial
} 
example, Bühler and Trapp (2009) demonstrate two potential channels: CDS premia can be affected by overall liquidity in the bond market because the value of a bond that is delivered under default is likely to be affected by market liquidity. Second, bid-ask spreads in the CDS market itself can be enlarged by increases in overall market illiquidity. We choose this regressand because data on CDS spreads are available for a large cross section of countries over the relevant time period.

Of course, changes in country creditworthiness will also affect CDS spreads, so as in that paper we need to condition on country creditworthiness in order to isolate the movements in CDS spreads attributable to liquidity changes. This is problematic for the broad cross section that we use in our study, as many of the countries in our sample do not have widely-traded instruments that one might typically consider as potential indicators of changes in a country's creditworthiness. Aizenman and Pasricha (2010) use Economist Intelligence Unit data for their sample of emerging market economies, but such data is only available monthly. Accordingly, we attempt to control for default risk via our Google search proxy, and discuss this more below.

As we discuss below, we are aware that our control for default risk is unlikely to be perfect; we try to be appropriately conservative in our interpretation. Still, our approach has advantages. For instance, because we use a panel of diverse countries, there is no issue of selection bias; we include countries that did not receive swaps, as well as those that did.

Our initial specification is:

and vary through time," and present a number of methods for estimating liquidity premia, of which the first relies on CDS spreads. Alternatively, Brigo, et al (2010) provide over 40 references in "Credit Default Swaps Liquidity Modeling: A Survey."

${ }^{14}$ We examined two additional specifications. First, we added the variables of interest on their own, i.e. not interacted with the TAF volume and tenor. The results for the interactive variables were much the same as those reported for our base specification, while the variables of interest failed to enter on their own at statistically significant levels. These results are shown in Table A1. Second, we conducted an event study specification adding the average implications of the TAF auctions across the sample along with the interactive slope and conditioning variables used in our base specification. Here the results were disappointing, as can be seen in Table A2, where the additional variable is labeled auction. These results mirror the weak event study results in the literature. 


$$
\begin{aligned}
& \Delta C D S_{i t}=\alpha_{i}+\theta_{t}+\beta_{1} \text { Exposure }_{i t} \cdot S P 500_{t}+\beta_{2} \text { Exposure }_{i t} \cdot \text { auction }_{t-1} \\
& +\beta_{3} \text { Transp }_{i t} \cdot \text { auction }_{t-1}+\beta_{4} \text { Illiquid }_{i t} \cdot \text { auction }_{t-1}+\beta_{5} \triangle \text { Default }_{i t}+\epsilon_{i t} .
\end{aligned}
$$

where $\triangle C D S_{i t}$ represents the percentage change in CDS spreads on country $i$ sovereign debt during week $t ; \alpha_{i}$ is a country dummy; Exposure $i t$ represents exposure to the United States, measured as discussed above; $S P 500_{t}$ represents the annualized percentage change in the $\mathrm{S} \& \mathrm{P} 500$. auction a $_{t-1}$ is equal to the sum of the volume of each auction of funds obtained through Federal Reserve swap lines during week $t-1$ times the average tenor of those auctions in weeks where auctions took place, and 0 in weeks with no auctions ${ }^{15}$ Transp $_{i t}$ represents dollar asset transparency, measured as the ratio of dollar equity holdings to the sum of holdings of dollar equities plus short and long term US corporate debt plus short and long-term US government agency debt 16

Illiquid $_{i t}$ represents asset illiquidity, measured as the ratio of short-term US liabilities to total exports; $\triangle$ Default $_{i t}$ conditions for changes in perceived default risk, based on our proxy from Google search, discussed below; and $\epsilon_{i t}$ is a disturbance term, assumed to be well behaved.

Our three variables of interest are the interactive terms representing the relative impact of the auctions on country $i$ dollar liquidity by exposure, asset transparency, and illiquidity: Exposure Ex $^{\text {. }}$ auction $_{t-1}$, Transp $_{i t} \cdot$ auction $_{t-1}$, and Illiquid $_{i t} \cdot$ auction $_{t-1}$.

The remainder of the variables are nuisance terms meant to capture other potential determinants of movements in sovereign CDS spreads, including Exposure $e_{i t} \cdot S P 500_{t}$, which is meant to pick up the impact on country $i$ of other economic developments in the US, $\triangle$ Default $_{i t}$ which is our Google measure meant to capture changes in the public's perception of default risk in country $i . \alpha_{i}$

\footnotetext{
${ }^{15}$ We use lagged weeks for the auction variable because many auctions took place late in the week, requiring some time for the market response in terms of the impact on other nations to be felt. Recall that these auction events have all been previously announced, and hence are not surprises.

${ }^{16}$ The intuition behind this definition of asset transparency is that the underlying values of US corporate debt and US long and short term agency debt is more opaque than those of standard US equities. Agency debt included in this measure include securities issued by U.S. government agencies or federally-sponsored enterprizes.
} 
and $\theta_{t}$ represent country and time dummies respectively ${ }^{17}$ The time fixed effects address a number of issues: the foreign TAF auctions were just one component of a number of policy responses by the Federal Reserve, as well as both the US Treasury, and Treasuries and central banks around the world. In addition, the composition of borrowers and the size and tenor of swap arrangements varied over the course of the policy as the swap programs were expanded. However, these fixed effects would be collinear with the auction $_{t-1}$ variable, as the timing, total volume and average tenor of auctions are common across countries 18

\subsection{Data}

\subsubsection{Standard data}

Our full sample is based on weekly data, and runs from December 10, 2007 to December 31, 2009. Our sample is a broad panel of emerging market and smaller developed economies, and includes 30 OECD and 38 non-OECD countries. We designate countries as OECD or non-OECD based on OECD membership in 2010.

We consider two types of measures of "exposure" to the United States. First, we consider trade-related measures, such as Exports, Imports and total Trade with the United States, as a share of total global trade. These variables are closer to the explicit model above, in the sense that we would expect that agents with more trade with the United States would be more likely to find themselves with potentially profitable trade opportunities with US nationals. We use monthly data on trade exposure to the United States from the IMF Direction of Trade statistics.

We also consider a variety of measures of asset exposure, including Assets $(T I C)$, which measures total holding of US assets based on TIC data as a share of global assets measured using

\footnotetext{
${ }^{17}$ While our specification is of weekly frequency, we only use monthly time dummies in the above specification. When we use weekly time dummies, all of the variables, including both our variables of interest and the nuisance parameters are very insignificant, as can be seen in Table A3 in the appendix.

${ }^{18}$ We examine the possibility of extra sensitivity in the countries directly receiving the auction funds below.
} 
the IMF CPIS data set, as well as two subsets of this data, Debt, and LTDebt, which measure total claims on US debt and total claims on US log-term debt respectively. Both numerator and denominator of these variables are available only annually ${ }^{19}$ Assets $(C P I S)$ represents an annual proxy for US asset exposure as a share of total global asset holdings, according to the IMF CPIS data set ${ }^{20}$ Estimation is done by OLS using robust standard errors clustered by country.

Data on foreign central bank auctions was obtained from the Federal Reserve Board of Governors, as were the details of announcements concerning changes in the Federal Reserve's swap program. We condition auction "events" for two characteristics: volume in overall dollar value and average tenor in days of length of contracts auctioned. The latter adjustment is important because securities auctioned varied from high maturities of 95 days to maturities as low as one day, representing substantially different levels of effective liquidity injections per dollar issued.

We obtain weekly percentage changes in CDS spreads and S\&P500 returns from Bloomberg.

\subsubsection{Default risk proxy from Google search}

Our primary non-standard data series is a proxy for perceived changes in country creditworthiness. As discussed above, we follow Aizenman and Pasricha (2010) in using differences in CDS spreads as our indicator of liquidity risk. Of course, changes in country creditworthiness will also affect CDS

\footnotetext{
${ }^{19}$ The TIC data is annual, based on exposure in June, while the CPIS data is annual, based on December exposure. We use TIC data for a given year as a proxy for exposure from July of the previous year to June of the current year, and use CPIS data for a given year as a measure of exposure from January to December of that same year. Ratios are then constructed from these monthly series as global exposure is only available from the CPIS data set. This led to some calculated ratios for these variables having implausible values, either less than 0 or greater than 1 . In response, we censor these variables to have minimum value 0.01 and maximum value 1 . Note that while the asset exposure variable only changes annually, the interactive variables in question are weekly, fluctuating with the changes in the auction $_{t-1}$ variable.

${ }^{20}$ Below, we report results based on trade and asset exposure as separate specifications. However, we also ran specifications with a form of both types of exposure included, and obtained similar results. We also investigate a number of alternative exposure measures. First, we normalize exposure by country GDP instead of global exposure. Second, we account for the fact that exposure to Europe is likely to be poorly measured because European assets are often held in tax havens in other countries in two ways: we look at bank exposure to the US, which is available consistently for all countries, and we also aggregate across the euro area. Our results are largely robust to all of these alternative exposure measures, as shown in appendices A4, A5, and A6.
} 
spreads, so we need to condition on country creditworthiness in order to isolate the movements in CDS spreads attributable to liquidity changes, as those authors do. This is problematic for the broad cross section that we use in our study, as many of the countries in our sample do not have widely-traded instruments that one might typically consider as potential indicators of changes in a country's creditworthiness. Aizenman and Pasricha (2010) use Economist Intelligence Unit data for their sample of emerging market economies, but such data is only available monthly.

In response, we use weekly search data obtained from Google Insights for Search. Based on their own description [e.g. Google (2011)], Google Insights for Search analyzes a portion of worldwide Google web searches from all Google domains to compute how many searches have been done for a chosen group of terms relative to the total number of searches done on Google over time.

Google search data has been used in a number of studies. Choi and Varian (2009) use search data results to predict levels of economic activity for automobile sales and unemployment figures. Mondria, Wu, and Zhang (2010) find that increased search volume on Google is associated with greater inward investment and Da, Engelberg, and Gao (2011) demonstrate that increased activity is associated with temporary increases in equity values. In both of these studies, the effect is attributed to increased "attention."

Such real-time data is most often used to describe current economic conditions, rather than forecast future ones, in a growing application commonly referred to as "nowcasting." Studies have verified a number of cases where the Google search data have added information over and above that available from other sources [e.g. Varian (2010) and Kholodin, Podstawski, and Siliverstovs $(2010)]$

This is the sense in which we use the Google search data in our study. To measure changes in the perceived sovereign risk of a country, we use the relative incidence of searches of words related to default risk combined with that country's name. The percentage change in search volume for a given country combined with these default-related terms is then used as as a proxy for changes in 
concerns about default risk about that country. ${ }^{21}$

A number of features of Google Insights should be pointed out. Responses are reported on a scale of 0 through 100. Figures are scaled by the highest volume response, which is given score 100. Remaining figures are then scored as their values as a share of the top reported value. Google also normalizes its series by a common variable, so values represent likelihoods of searches for a given country, rather than the absolute number of searches. This leaves all series country-specific. However, these series suit our purposes because we are only interested in the changes in our series over time, and the normalizations drop out.

One potential problem with our use of Google Insights as a proxy for changes in perceived default risk is that for proprietary reasons Google does not provide numerical values for responses when they fall below a certain threshold. For our purposes here, we proxy the numerical value for such observations as equivalent to the lowest reported value, which is clearly an upper-bound estimate of its true value.

To increase the potential correlation between our proxy and actual perceptions of creditworthiness, we choose a set of credit-risk related search words that are correlated with observed changes in perceived creditworthiness. Obviously, other estimates of changes in perceived country risk are not available at the high frequency that we use in our cross-section panel; this is what drove us to use the Google search data in the first place. We therefore examine the validity of our proxy by determining its correlation with other measures of default risk at the lower frequencies at which those other measures are available.

We begin with a set of 33 default-related words. While it would be desirable to evaluate all of the possible combinations of these words, this methodology is not possible because of restrictions

\footnotetext{
${ }^{21}$ We freely acknowledge that our Google data might be a better gauge of popular concern about a particular country's default risk, rather than that held by market professionals, as they more likely use propriety sources of data. Still, our results below demonstrate that there is a correlation with sovereign credit ratings, which presumably reflect the opinions of market participants rather than the general public.
} 
placed by Google on the total number of searches that can be conducted on a single day ${ }^{22}$

In response, we developed a simple algorithm to choose the set of default-related terms we use to conduct the Google searches. First, we generated a full set of searches with each of the countries in our sample and one of the 33 default-related terms. We then regressed panels of these combinations of searches by countries and single default-related terms on monthly changes in Fitch sovereign ratings. We examine three series, foreign and domestic long term debt obligations and short-term foreign obligations. Of these, we were most interested in the results for foreign long-term obligations.

Our results for foreign long-term obligations are shown in Table A7 23 We found three words which entered significantly for all of the Fitch series: crisis, financial, and freeze 24 We then ran searches with these three terms and one of the remaining words. This yielded six words which improved the fit of the Google searches with in-sample changes in Fitch ratings: "credit", "debt", "exposure", "liability", "recession", and "safety". We chose the set of four words that fit the best, which added the word "recession." We then examined the implications of adding a fifth word from this list. None of these improved the fit of our ratings changes regressions, so we settled on searches mentioning a country and one of four default-related terms: crisis, financial, freeze, and recession.

Correlations in the data between search volume and bond ratings changes are demonstrated in Figure 3. We plot the Google series for four countries, Ireland, Greece, Iceland, and Latvia. Data availability differs by country, from as far back as 2004 for Ireland to 2008 for Iceland. However, all countries have data for the bulk of the crisis period. It can be seen that there is a lot of variability in the data, but all four countries appear to have credit downgrading episodes that correspond to local spikes in the Google series. Of course, there are lots of other spikes in the Google data that

\footnotetext{
${ }^{22}$ We search over 112 countries for every variety of default-related terms.

${ }^{23}$ Results for domestic long-term and foreign short-term are available on request.

${ }^{24}$ We also found that the word "danger" entered significantly for short-term obligations, but neither of the other series. When adding this word to the 3 word base, however, the quality of fit deteriorated. In response, we continued with the 3 word base discussed in the text.
} 
do not correspond to a credit downgrading event, and the relationship does not always appear to be exactly contemporaneous. Still, we would at least like to feel certain that changes in the Google ratings do correspond to changes in search volumes.

To investigate this question more formally, we considered the following panel specification for our entire cross-country sample:

$$
\Delta \text { Rating }_{i t}=\alpha_{t}+\theta_{i}+\beta_{1} \Delta \text { Google }_{i t}+\epsilon_{i t} .
$$

where $\Delta$ Rating $g_{i t}$ is the change in country $i$ 's Fitch credit rating at time $t$, with one point for each change, $\alpha_{t}$ and $\theta_{i}$ are time and country dummy variables respectively, $\Delta G o o g l e_{i t}$ is the variable of interest, the percentage change in the Google default proxy (hereafter referred to as default), and $\epsilon_{i t}$ is an independent error term, assumed to be well-behaved.

Our results are shown in Table 3 for both the full time series over which Google search data is available and a smaller time series that corresponds to the period covered in our study below. Data is monthly, and our specification includes country and time fixed effects.

It can be seen that there is a strong negative relationship between ratings changes and Google search volumes in our full data panel, that is robust across the three different asset categories whose ratings we consider. The estimated coefficient values suggest that a doubling of Google search volume is predicted to, for example, result in a downgrade of foreign short-term debt equal to 6 basis points, even after controlling for changes in global conditions through the time fixed effects, for the time series corresponding to our study below.

We find it reassuring that the Google search volume data tracks this manifestation of changes in expectations about sovereign default risk in the manner we desire. We therefore use changes in the volume of Google index searches for a country name and one of the words associated with sovereign risk listed above as a proxy for changes in the public perception of default risk for that 
country 25

\subsection{Results}

Our base specification results are shown in Table 4. In terms of the three variables of interest, the interactive Exposure variable consistently obtains a negative sign, either for trade-related measures of exposure (Models 1 through 3), or for the measures of asset exposure (Models 4 through 7), with the exception of Model 5 which obtains the predicted negative sign, but is insignificant. ${ }^{26}$

Moreover, the coefficient estimates suggest that discrepancies across countries with different exposure levels are substantial. Our dependent variable is measured in percentage changes in CDS spreads, which implies that the predicted decrease in CDS spreads from a week with average auction volume and tenor in our sample would be 36.5 basis points larger for a country with one standard deviation higher trade exposure to the United States as measured by our Trade variable. Similarly, the predicted decrease in CDS spreads from a week with average auction volume and tenor in our sample would be 26.2 basis points larger for a country with one standard deviation higher asset exposure to the United States, as measured by our Assets(TIC) variable ${ }^{27}$

The interactive Transp variable robustly enters significantly with its unpredicted negative sign. This suggests that this variable is likely picking up some benefit from having a relatively large stock of US Treasuries that allowed countries to fare disproportionately well on weeks with TAF auctions that is outside of our theoretical model. It may be that those countries whose public and private agents hold a transparent US dollar portfolio - measured in our data as the share

\footnotetext{
${ }^{25}$ As a robustness check, we also took an ad hoc set of default-related terms and used search results for that string instead of the stepwise procedure discussed above. These words included "risk", "default", "recession", "deficit", "debt", "crisis", and bankruptcy. Our reported results were robust to this alternative proxy, and are shown in appendix Table A8.

${ }^{26}$ We ran the Wooldridge (2002) test for serial correlation in panel estimation for all seven of our base specification models. In all cases, we could not reject the null of no serial correlation. These results are available upon request.

${ }^{27}$ These calculations are based on the standard deviation of of the Trade exposure measure in our sample being 0.10 , the mean values of weekly auction volume*tenor being 1.15 , and the standard deviation of the Assets(TIC) variable being 0.41
} 
of long and short-term US treasuries to treasuries plus agency debt plus corporate debt - have a greater need for dollar liquidity during crisis periods than those that do not. This need may be time-varying, and therefore not conditioned for by our country fixed effects. ${ }^{28}$

Finally, the interactive Illiquid variable is insignificant throughout.

Among our nuisance parameters, the Exposure $_{i t} \cdot S P 500_{t}$ variable is again significant with its predicted negative sign throughout, while the $\triangle$ Default $_{i t}$ obtains its predicted positive coefficient estimate, but is statistically insignificant throughout, with the exception of Model 5 which measures exposure as the share of U.S. asset holdings using the CPIS data.

We conclude that the foreign TAF auctions disproportionately benefited those countries more exposed to the United States, either through trade or asset exposure. However, we obtained exactly the wrong sign for the opaqueness of US asset holdings, suggesting that we pick up an effect not predicted by our theory. Finally, we obtained insignificant results for the interactive illiquidity variable.

\section{Robustness Tests}

In this section, we subject our chosen base specification to a number of robustness checks, including using alternative measures of illiquidity, alternative sub-samples of the data, and examining the impact of announcements concerning the international swap arrangements, rather than the auctions themselves 29

\footnotetext{
${ }^{28}$ Data by country for disaggregated holdings of US assets is limited, but these results are robust to an alternative specification for the Transp variable which treats US government agency debt as as transparent as US equities. The results for the other interactive variables are also robust to dropping the transparency variable altogether.

${ }^{29}$ We also conducted a number of other robustness tests which are reported as appendix tables. First, we considered changes in exchange rates, both as a potential additional independent variable, as they might represent an alternative driver of CDS spreads, and as a dependent variable, as changes in exchange rate pressure might be an alternative outcome of the auctions. Our results are reported in Tables A9 and A10 respectively, where the variable $\Delta$ exrate represents the percentage change in the exchange rate. Our base regression results are robust to the inclusion of the exchange rate as an additional right hand side variable. However, we get far different results for the impact of the auctions on exchange rates. We find that illiquid countries experienced significantly greater relief in exchange
} 


\subsection{Alternative Illiquidity Measures}

We consider three alternative liquidity measures. These include short-term debt as a share of GDP, the ratio of short-term debt to international reserves, and the "Greenspan-Guidotti" illiquidity measure, which is measured as the ratio of short-term debt minus international reserves to international reserves ${ }^{30}$ Except for these alternative illiquidity measures, we keep our base specification and again consider all seven exposure measures used above.

Our results are shown in Table 5. For space considerations, we only report the results for the three interactive variables of interest ${ }^{31}$ We first measure illiquidity as the ratio of short-term debt to GDP. It can be seen that the results are qualitatively identical to those in our base specification. The interactive exposure variable are significantly negative throughout, with the exception of Model 5 with similar coefficient values. The interactive transparency variable again enters significantly with a negative sign throughout, while the interactive illiquidity variable is insignificant.

We next measure illiquidity in terms of the ratio of short-term debt to reserves. This specification again obtains a statistically significant negative sign for all of the interactive exposure variables except Model 5, negative and significant coefficient estimates on the interactive transparency variables, and insignificant coefficient estimates for the illiquidity measure.

Finally, we use the "Greenspan-Guidotti" measure of illiquidity, namely the ratio of short-term debt to reserves minus one. The interactive exposure measure again enters significantly with its expected negative sign for all of the trade-related exposure measures, but is significant for only

rate pressure, usually at statistically significant levels, but the exposure variables are all insignificant. Of course, many things may drive exchange rate movements beyond the explicit model above and in patterns that are not well understood by economists. We also examined changes in LIBOR-OIS spreads as an alternative dependent variable. We have a much smaller sample, as we are limited to 8 countries. The results are shown in Table A11. We continue to obtain negative coefficient estimates throughout for exposure, but only at statistically significant levels in two of the 7 specifications. However, an additional specification is significant at a $10 \%$ confidence level.

${ }^{30}$ The latter two terms are similar, but the interaction with the volume and tenor variables imply that they are not identical, as shown in the results.

${ }^{31}$ The full results are in appendix tables A12, A13, and A14. 
one of the financial exposure variables, that of Model 5 which measures exposure as the ratio of holdings of US assets as a share of total global asset holdings.

The interactive transparency variable continues to obtain a negative coefficient, but is now insignificant for most of the asset exposure measures (Models 5, 6, and 7). The interactive transparency and illiquidity variables are insignificant throughout 32

While the financial exposure measures were a little weaker using the "Greenspan-Guidotti" measure of illiquidity, overall the results of the base regression reported above appear to be robust to the alternative illiquidity measures we entertained here.

\subsection{Alternative Samples}

We next consider dividing up our pooled sample into OECD and non-OECD sub-samples. It is quite plausible that these groups experienced different impact of the foreign TAF auctions. We again use our base specification with the seven different exposure measures.

The results for the OECD sub-sample are shown in Table 6. These results are quite similar to those in our base specifications, and stronger in some dimensions. The exposure variables all enter significantly with their expected negative signs including that of Model 5 this time. Moreover, the coefficient values are somewhat larger than those we obtained for the full sample. Moreover, the coefficient estimates suggest that discrepancies across countries with different exposure levels are again substantial.

For the OECD sub-sample, we find that the predicted decrease in CDS spreads from a week with average auction volume and tenor in our sample would be 44.8 basis points larger for a country with one standard deviation higher trade exposure to the United States as measured by our Trade variable. Similarly, the predicted decrease in CDS spreads from a week with average auction volume

\footnotetext{
${ }^{32}$ One problem with our liquidity measures is that Ireland is a major outlier. Nevertheless, we obtained similar results throughout after dropping Ireland.
} 
and tenor in our sample would be 33.1 basis points larger for a country with one standard deviation higher asset exposure to the United States, as measured by our Assets (TIC) variable 33

Among the other variables, the interactive transparency and illiquidity variables are insignificant throughout, with the exception of Model 3, where illiquidity enters at a $5 \%$ confidence level with an incorrect positive sign. The $S \& P 500$ variable again also enters consistently with its expected negative sign at statistically significant levels. The biggest change is in the performance of the Google-based default proxy. This variable now enters with its predicted positive sign at statistically significant levels for all of our specifications. It seems that this proxy is more adept at picking up changes in default perception among the OECD country sub-sample.

This perception is confirmed for the non-OECD country sub-sample, which yields much weaker results (Table A15). In particular, the Google-based proxy enters with the incorrect, although usually insignificantly for the non-OECD sub-sample. This discrepancy with the OECD sub-sample may reflect the fact that this crisis hit wealthier countries harder than emerging market economies [e.g. Rose and Spiegel (2012)]. It may also reflect the greater search volume found among OECD countries. Still, despite the poor performance of the default proxy, the remaining qualitative results are quite similar to those in the full sample.

\subsection{Announcement Effects}

We also examine the impact of the announcements listed in Table 1. We divide up the seven announcements listed into those applying to what we term the "major central banks," the ECB, the BOE, the SNB, the BOJ and the Bank of Canada, and those dealing with the central banks of other economies. We have three major bank announcement weeks: 1) The week including December 12, 2007, when the Federal Reserve initially announced the central bank swap programs with the

\footnotetext{
${ }^{33}$ These calculations are based on the standard deviation of of the Trade exposure measure in our sample being 0.08 , the mean values of weekly auction volume*tenor being 1.15 , and the standard deviation of the Assets(TIC) variable being 0.30
} 
ECB and the SNB, 2) the week including September 18, 2008, when swap lines were introduced with the BOJ, the BOE, the Bank of Canada and funds were increased for the ECB and the SNB, and 3) the week including October 13 and 14, 2008, when the ceilings on swap magnitudes were lifted with the ECB, the BOE, the SNB, and the BOJ. We have two weeks with major announcements concerning other central banks, including September 24, 2008, when swap lines were introduced with Australia, Sweden, Denmark, and Norway, and the week of October 28 and 29, 2008, when swap lines were introduced with the reserve banks of New Zealand, Brazil, Mexico, Korea and Singapore.

Unlike the anticipated auctions examined above, we consider the "event week" associated with the announcements as the week in which the announcement was made. The intuition behind this assumption is that information flows are likely to be close to instantaneous, while the liquidity effects of anticipated injections of capital on other countries may take some time to establish. We examine the impacts of these announcements by interacting our three variables of interest, Exposure, Transp and Illiquid with two announcement date dummies, labeled by the date of the first important announcement of that week.

The results for the major central bank announcements are shown in Table 7a. One can see that the impact of the announcements varied widely throughout the crisis. For the week of December 12,2007 , the interactive exposure variables are all insignificant. However, the transparency variables all now enter with their expected positive signs at statistically significant levels. Moreover, the interactive illiquidity variable enters with its expected negative sign throughout, although at statistically significant levels in only four of the seven specifications.

In contrast, all interactive variables were insignificant for the September 18, when swap lines were introduced for the BOJ, the BOE and the Bank of Canada.

For the the week including October 13 and 14, 2008, when the ceilings on swaps with the major central banks were lifted, the interactive exposure variable enters negatively throughout, and is 
statistically significant for all specifications, except Model 5. The interactive Transp variable again universally enters negatively at statistically significant levels. Moreover, the interactive illiquidity variable usually obtains a negative sign, but is insignificant throughout. The similarity between these results and those of our base regressions is striking. Of course, this announcement also coincided with the height of the crisis, a time when TAF auction activity was also peaking. The similarities with the results for auction volumes and tenors is therefore not surprising.

We next turn to the announcements concerning swap arrangements with other central banks. These are shown in Table 7b. In the September 24, 2008 announcement, when swap lines were introduced with Australia, Sweden, Denmark, and Norway, we obtain negative coefficient estimates on the exposure variable throughout, but only at statistically significant levels in Model 5. However, we again obtain positive and statistically significant coefficient estimates on the interactive transparency variable throughout. The illiquidity measure is universally insignificant.

The final announcement, that of October 28 and 29, 2008, when swap lines were introduced with the reserve banks of New Zealand, Brazil, Mexico, Korea and Singapore, seems to be more similar to the October 13 announcement discuss above. The interactive exposure variables enter negatively throughout,and at $1 \%$ confidence levels for five of the seven specifications. The interactive transparency variable again enters negatively for all specifications at statistically significant levels throughout, while the illiquidity variable is mixed and insignificant for all specifications except Model 2.

Overall, the results were mixed across event dates. The results for two of the announcement weeks - October 13 and 14, 2008, when the ceilings on swaps with the major central banks were lifted, and October 28 and 29, 2008, when swap lines were introduced with the reserve banks of New Zealand, Brazil, Mexico, Korea and Singapore - were very similar to those obtained for base specification of the actual auctions above. In particular, we obtained statistically significant coefficient estimates for all of our US exposure measures. However, for two of the other event 
weeks (that containing December 12, 2007 when the swap lines were originally introduced and that containing September 24, 2008, when the swap program was broadened to include Australia, Sweden, Denmark, and Norway) the coefficient estimate on the interactive transparency variable entered for the first time with its predicted positive coefficient estimate at statistically significant levels.

It seems plausible that the results for the announcements in October were similar to those of the actual auctions because it was during that month that auction volume peaked. However, it seems difficult to draw parallels between the two event dates that yielded significant coefficient estimates for the interactive transparency variable for the first time. Both involved an expansion of the swap program, the first was the actual initiation of the program while the second expanded it beyond the major central banks. The significant coefficient estimate obtained for the transparency variable suggests that these expansions were of particular importance to countries with more opaque US asset holdings.

\subsection{Differential Impacts for Swap Partner Countries}

While the evidence above suggests that the broad cross section was affected by the international swap arrangements, it seems likely that the principal countries directly involved in those swaps may have been more affected on average. To investigate that possibility, we add slope dummies for countries that were direct auction recipients. We add a variable direct $_{t-1}$ that takes value the value of auction volume to country $i$ times the average tenor of the securities auctioned at time $t-1$ if country $i$ received TAF funds in period $t-1$, and 0 otherwise to capture the additional impact on CDS spreads of being a direct recipient of the TAF funds. We also add three interactive variables to our base specification: Exposure $_{i t} \cdot$ direct $_{t-1}$ which interacts the exposure variables with a variable direct $_{t-1}$, which takes the value of auction volume to country $i$ times the average tenor of the securities auctioned at time $t-1$ if country $i$ received TAF funds in period $t-1$, and 
0 otherwise, Transp $_{i t} \cdot$ direct $_{t-1}$, and Illiquidity $_{i t} \cdot$ direct $_{t-1}$. These allow the direct effect to vary by country characteristics according to the predictions of the theory ${ }^{34}$

The results are shown in Table 8 . The direct $_{t-1}$ variable obtains a positive sign throughout, but is insignificant at a $5 \%$ confidence level. The slope coefficients of the trade-related interactive direct exposure variables are negative throughout, except for Model 5, but are only statistically significant in Models 6 and 7. We also obtain negative, but usually insignificant coefficient estimates for the direct interactive illiquidity variables, with the exceptions again being Models 6 and 7 , while the direct interactive transparency variable is insignificant throughout. The results for the overall variables from our base specification are little changed by the inclusion of these direct impact variables. In particular, the interactive exposure measures enter significantly with their predicted negative signs for all specifications except Model 5. As a result, we conclude that the international swaps did indeed serve to promote general dollar liquidity, and gave little measurable special assistance to those countries who were the direct recipients of the funds.

Finally, we turn to the countries explicitly named in announcements concerning changes in the swap programs to examine if those countries exhibited additional sensitivity to country characteristics relative to the non-partner countries. We run our specification for announcements with the Exposure Ex $_{i t}$ Transp $_{i t}$, and Illiquidity $i t$ variables interacted with two new variables major and other. major is a dummy variable that takes value one for the "major central banks," namely the $\mathrm{ECB}$, the SNB, the BOE, the BOJ, and the Bank of Canada, on dates when they are specifically mentioned in Federal Reserve Announcements, and 0 otherwise, and take value 0 for the other central banks in our sample throughout. Similarly, dummy variable other takes value one for the other central banks in our sample on dates when they are specifically mentioned in Federal Reserve Announcements, and value 0 otherwise, and value 0 for the major central banks throughout. We pool across these two groups of central banks because there are too few mentioned in any individual

\footnotetext{
${ }^{34}$ Because these variables are country-specific, there is the possibility of endogeneity bias, as swap partners may receive funds when conditions are at their worst.
} 
announcement to obtain an estimate of any extra sensitivity directly-named countries might have to these announcements. The cost of this aggregation is that we must constrain the coefficients to be identical across countries within these groups. We ran the specification including both the announcement events and the actual auction data, with the new interactive terms added. To conserve on space, we only report the coefficient estimates on the slope coefficients, which can be found in Table 935

The interactive exposure variables obtain negative coefficient estimates throughout, both for announcements involving major and other central banks. However, they are only statistically significant half of the time. The interactive transparency variable for swap announcements concerning major central banks is negative, and significant in four of the seven specifications. However, the coefficient for announcements concerning swap arrangements with other central banks, the interactive transparency variable is universally positive and statistically significant in six of the seven specifications. This suggests that among the non-major central banks countries, there was additional sensitivity to the opaqueness of US asset holdings among actual swap partners. Lastly, there was little observable difference in sensitivity to swap announcements by illiquidity among swap partner countries, as our coefficient estimates by this characteristic were mixed.

Overall, we did not observe much heterogeneity between the responsiveness of actual swap partners and the other countries in our sample, suggesting that the swaps acted more as a general injection of dollar liquidity worldwide than as funds that disproportionately assisted the countries towards whom these swaps were targeted. However, one notable exception was the interactive transparency variable for other central banks. Our previous results suggested that the September 24, 2008 announcement introducing swap lines to Australia, Denmark, Sweden and Norway disproportionately benefited countries with more opaque US portfolios. Our results in this section suggest that the swap partner countries were even more sensitive to asset opaqueness.

\footnotetext{
${ }^{35}$ The full specification can be found in appendix Table A16.
} 


\section{Conclusion}

This paper argues that the appreciation of the U.S. dollar exhibited at the height of turbulence during the recent global financial crisis suggests that there was a global dollar shortage. Models with illiquidity in dollar markets can mimic this behavior, as declines in some dollar asset values - as occurred to toxic US during the global financial crisis such as mortgage-backed securities can result in the appreciation of other dollar assets that can serve as substitutes in the provision of liquidity services. This includes currency, which is a potential explanation of the surprising dollar exchange rate appreciation that occurred at the height of the global financial crisis. These models predict that injections of dollar liquidity, as occurred during the TAF auctions of the major foreign central banks, will have a disproportionately beneficial impact on economies that are more heavily exposed to the United States through trade or financial channels, have more opaque assets, or have deeper illiquidity problems.

We take these predictions to a cross-country panel, examining the impact of the TAF auctions on CDS spreads in a format that avoids a number of the problems encountered by the event studies in the existing literature. Our results suggest that the benefits of the TAF auctions were disproportionately enjoyed by those countries that had greater trade or asset exposure to the United States. We obtain weaker or incorrect results for national differences in the impact of the auctions by the transparency of dollar holdings and measures of illiquidity.

Looking at announcements concerning the TAF auctions, we found a discrepancy between those announcements that came at the height of the financial crisis and other announcements in our sample. For announcements in October 2008, we obtained results that were similar to those observed for the actual auctions throughout. In particular, we observed greater sensitivity to the announcements among countries that had greater trade or financial exposure to the United States. In contrast, for two of the other three announcements, we observed greater sensitivity among countries holding more opaque asset portfolios, again in keeping with the predictions of the theory. 
Overall, our results suggest that the swap arrangements disproportionately benefited those countries that were more exposed to the United States, and we also obtain some evidence of disproportionate benefits to countries holding more opaque US asset portfolios. As suggested by theory, this is what one would expect from an effective dollar liquidity injection. Our results therefore support the claim that the swap arrangements provided tangible liquidity improvements. However, we should stress that we make no claims about the welfare implications of the swap arrangements here. 


\section{References}

Aizenman, J., and G. K. Pasricha (2010): "Selective Swap Arrangements and the Global Financial Crisis:," International Review of Economics and Finance, 19(3), 353-365.

Baba, N., and F. Packer (2009a): "From Turmoil to Crisis: Dislocations in the FX Swap Market Before and After the Failure of Lehman Brothers," Journal of International Money and Finance, $28,1350-1374$.

Baba, N., and F. Packer (2009b): "Interpreting Deviations from Covered Interest Parity During the Financial Market Turmoil of 2007-2008," Journal of Banking and Finance, 33, 1953-1962.

Bernanke, B. S. (2009): "Four Questions About the Financial Crisis," Speech at the Morehouse College, Atlanta Georgia.

Brigo, D., and M. Predescu, and A. Capponi (2010): "Credit Defaqult Swaps Liquidity Modeling: A Survey," mimeo, Cornell University.

Brunnermeier, M. K. (2009): "Deciphering the Liquidity and Credit Crunch 2007-2008," Journal of Economic Perspectives, 23(1), 77-100.

Bühler, W., and M. Trapp (2009): "Time-Varying Credit Risk and Liquidity Premia in Bond and CDS Markets," CFR Working Paper 09-13.

Chinn, M., and J. A. Frankel (2007): "Will the Euro Eventually Surpass the Dollar as Leading International Reserve Currency?," in G7 Current Account Imbalances: Sustainability and Adjustment, ed. by R. Clarida, pp. 283-335. NBER and University of Chicago Press.

Choi, H., and H. Varian (2009): "Predicting the Present with Google Trends," mimeo.

Da, Z., J. Engelberg, and P. Gao (2011): "In Search of Attention," forthcoming, Journal of Finance. D'Amico, S., and T. B. King (2011): "Flow and Stock Effects of Large Scale Treasury Purchases," mimeo, February.

Engel, C. (2009): "Exchange Rate Policies," Federal Reserve Bank of Dallas Staff Paper No. 8, November.

Fratzscher, M. (2009): "What explains global exchange rate movements during the financial crisis?," Journal of International Money and Finance, 28, 1390-1407.

Geromichalos, A., and I. Simonovska (2011): "Asset Liquidity and International Portfolio Choice," NBER Working Paper no. 17331, November.

Goldberg, L., and C. Tille (2008): "Vehicle Currency Use in International Trade," Journal of International Economics, 76, 177-192.

Goldberg, L. S., C. Kennedy, and J. Miu (2010): "Central Bank Dollar Swap Lines and Overseas Dollar Funding Costs," Federal Reserve Bank of New York Staff Report no. 429.

Google (2011): "Google Insights for Search," http://www.google.com/insights/search/.

Hale, G. B., and M. M. Spiegel (2008): "Who Drove the Boom in Euro-Denominated Bond Issues?," 
Federal Reserve Bank of San Francisco, Working Paper 08-20.

Hamilton, J. D., and C. Wu (2012): "The Effectiveness of Alternative Monetary Policy Tools in a Zero Lower Bound Environment," forthcoming, Journal of Money, Credit and Banking.

Hibbert, J., A. Kirchner, G. Kretzschmar, R. Li, and A. MacNeil, "Liquidity Premium: Literature Review of Theoretical and Empirical Evidence," Research Report v. 1.1, September.

Ho, C., and F.-L. Michaud (2008): "Central Bank Measures to Alleviate Foreign Currency Funding Shortages," BIS Quarterly Review.

Hui, C.-H., H. Genberg, and T.-K. Chung (2010): "Funding Liquidity Risk and Deviations from Interest-Rate Parity During the Financial Crisis of 2007-2009," International Journal of Finance and Economics, n/a, doi: 10.1002/ijfe.427.

Kholodin, K. A., M. Podstawski, and B. Siliverstovs (2010): "Do Google Searches Help in Nowcasting Private Consumption?: A Real-Time Evidence for the US," KOF Swiss Institute Working Paper No. 256, April.

Kiyotaki, N., and R. Wright (1993): "A Search-Theoretic Approach to Monetary Economics," American Economic Review, 83(1), 63-77.

Krishnamurthy, A., and A. Vissing-Jorgensen (2011): "The Effects of Quantitative Easing on Interest Rates," mimeo.

Krugman, P. (2007): "Will there be a dollar crisis?," Economic Policy, 22(51), 435-67.

Lagos, R., and G. Rocheteau (2008): "Money and Capital as Competing Media of Exchange," Journal Economic Theory, 142(1), 247-258.

Lagos, R., and R. Wright (2005): "A Unified Framework for Monetary Theory and Policy Analysis," Journal of Political Economy, 113(3), 463-484.

Lester, B., A. Postlewaite, and R. Wright (2011): "Information and Liquidity," Journal of Money, Credit and Banking, Supplement to volume 43, 355-378.

Lester, B., A. Postlewaite, and R. Wright (2012): "Information, Liquidity, Asset Prices and Monetary Policy," forthcoming, Review of Economic Studies.

Liu, Q. (2010): "Goods Market Frictions and Real Exchange Rate Puzzles," mimeo.

McAndrews, J., A. Sarkar, and Z. Wang (2008): "The Effect of the Term Auction Facility on the London Inter-Bank Offered Rate," FRBNY Staff Report no. 335.

McCauley, R. N., and P. McGuire (2009): "Dollar appreciation in 2008: safe haven, carry trades, dollar shortage and overhedging," BIS Quarterly Review, 85-93.

Mondria, J., T. Wu, and Y. Zhang (2010): "The Determinants of International Investment and Attention Allocation," Journal of International Economics, 82, 85-95.

Obstfeld, M., J. C. Shambaugh, and A. Taylor (2009): "Financial Instability, Reserves, and Central Bank Swap Lines in the Panic of 2008," American Economic Review: Papers and Proceedings, $99(2), 480-486$. 
Peter, G. v., and P. McGuire (2009): "The US Dollar Shortage in Global Banking and the International Policy Response," BIS Paper 291.

Rose, A. K., and M. M. Spiegel (2010): "Cross-Country Causes and Consequences of the 2008 Crisis: International Linkages and American Exposure," Pacific Economic Review, 15(3), 340-363.

Rose, A. K., and M. M. Spiegel (2012): "Cross-Country Causes and Consequences of the 2008 Crisis: Early Warning," forthcoming, Japan and the World Economy.

Rose, A. K., and M. M. Spiegel (2011): "International Dollar Illiquidity and Central Bank Swap Arrangements," mimeo.

Taylor, J. B., and J. C. Williams (2008): "Further Results on a Black Swan in the Money Market," mimeo.

Taylor, J. B., and J. C. Williams (2009): "A Black Swan in the Money Market," American Economic Journal: Macroeconomics, 1(1), 58-83.

Trejos, A., and R. Wright (1995): "Search, Bargaining, Money and Prices," Journal of Political Economy, 103(1), 118-141.

Varian, H. R. (2010): “Computer Mediated Transactions," American Economic Review, 100(2), $1-10$. 


\section{Appendix}

This appendix summarizes the model in Rose and Spiegel (2011), an international version of the search-based asset model of Lagos and Wright (2005), and its implications for the empirical specification in the paper. Detailed derivations of can be found in a technical appendix available online at http://www.frbsf.org/economics/economists/mspiegel/wp11-18appendix.pdf.

There are two countries in the model, $u$ and $r$, which can be interpreted as representing the United States and the rest of the world with identical preferences and production technologies. Country $z$ has world output share of $\tau_{z} ;(z=u, r)$, where $0 \leq \tau_{z} \leq 1$ and $\tau_{u}=1-\tau_{r}$.

In each period a continuum of infinitely lived agents participate in two distinct international markets: One is a Walrasian centralized global market, and another is a decentralized market, where pairs of buyers and sellers from the two countries are randomly matched. As in Lagos and Wright (2005) transactions in the decentralized market are characterized by a double-coincidence problem, which rules out barter, and anonymity, which rules out the provision of credit between matched agents. A tangible medium of exchange is therefore required for transactions to take place.

On each date, agents from country $z(z=u, r)$ can produce a tradable homogeneous good for the centralized market, $x$, using labor, $h_{z}$, according to the production function $x_{z}=h_{z}$. Utility is assumed to be concave in $x$ and negatively linear in $h$ according to $U\left(x_{z}\right)-h_{z}$ and $U^{\prime}(0)=\infty$, so that $x_{z}^{*}$, the optimal production of $x$ in each country satisfies $U\left(x_{z}^{*}\right)=1$.

Agents also produce a good, $q_{z}$, which is tradable in the international decentralized market. $q_{z}$ is produced at disutility $c\left(q_{z}\right)$, where $c^{\prime}>0, c^{\prime}>0$, and $c(0)=c^{\prime}(0)=0$. Agents value $q_{z}$ according to the concave function $v\left(q_{z}\right)$, where $v^{\prime}>0, v "<0, v(0)=0$, and $v^{\prime}(0)=\infty$, so that $q_{z}^{*}$, the optimal production of $q_{z}$ satisfies $v^{\prime}\left(q_{z}\right)=c^{\prime}\left(q_{z}\right)$. To highlight the role that differences in information sets and asset illiquidity play in determining outcomes, we assume that both $x$ and $q$ are homogeneous across countries.

Each country has a domestic money supply, which is in fixed supply, and a real asset that yields a dividend in the centralized market the following period. There are good and bad assets. Bad assets yield a zero dividend, while good assets yield a dividend of $\delta_{z}$ units of $x ; z=u, r$. Bad assets can be produced at zero cost.

Let $\phi_{z}$ and $\psi_{z}$ represent the values of money and real assets of country $z$ in the centralized market in terms of $x$ respectively. As in Lester, Postlewaite, and Wright (2012), agents can distinguish between bad and good assets in the centralized market, but in the decentralized market only informed agents can. Sellers who do not know the value of an asset will refuse to accept it at a positive price. As a result, bargaining only takes place where both agents are informed.

We focus on steady state equilibria. There is a fixed supply of trees in each country, $A_{z}$, and the supplies of both currencies grow at a constant rate, $\gamma_{z}$. Let $\widehat{k}$ represent the next period value of any variable $k$, so that $\widehat{M}_{z}=\gamma_{z} M_{z}$. Agents worldwide are assumed to share a common discount factor, $\beta$, and we assume that $\gamma_{z}>1>\beta$ for both countries ${ }^{36}$.

${ }^{36}$ If allowed, agents may choose to keep some of their assets out of the bargaining process in the decentralized 
All assets owned by agents are assumed to be brought into the decentralized market. We also assume that assets are "scarce," and therefore carry a liquidity value over their value in exchange the following day in the centralized market.

Agents' centralized market portfolios are comprised of $m_{z, u}$ units of country $u$ currency, $m_{z, r}$ units of country $r$ currency, $a_{z, u}$ units of country $u$ real assets, and $a_{z, r}$ units of country $r$ assets. Let $y_{z}$ represent income of an agent from country $z$ in the centralized market, which satisfies

$$
y_{z}=\phi_{u} m_{z, u}+\phi_{r} m_{z, r}+\left(\delta_{u}+\psi_{r}\right) a_{z, u}+\left(\delta_{r}+\psi_{r}\right) a_{z, r}
$$

Let $W\left(y_{r}\right)$ be the value function of an agent from country $z$ in the centralized market, and define $V_{z}\left(m_{z, u}, m_{z, r}, a_{z, u}, a_{z, r}\right)$ as the value function of an agent from country $z$ in the decentralized market with portfolio $\left(m_{z, u}, m_{z, r}, a_{z, u}, a_{z, r}\right)$. An agent from country $z$ solves

$$
\max _{x_{z}, h_{z}, \widehat{m}_{z, u}, \widehat{m}_{z, r}, \widehat{a}_{z, u}, \widehat{a}_{z, r}} W\left(y_{z}\right)=\left\{U\left(x_{z}\right)-h_{z}+\beta V_{z, u}\left(\widehat{m}_{z, u}, \widehat{m}_{z, r}, \widehat{a}_{z, u}, \widehat{a}_{z, r}\right)\right\}
$$

subject to

$$
x_{z} \leq h_{z}+y_{z}-\phi_{u} \widehat{m}_{z, u}-\phi_{r} \widehat{m}_{z, r}-\psi_{u}\left(\widehat{a}_{z, u}\right)-\psi_{r}\left(\widehat{a}_{z, r}\right)+T_{z}
$$

where $T_{z}$ is a lump-sum transfer returned to private agents in country $z$ from revenues generated by money creation, $T_{z}=\left(\gamma_{z}-1\right) M_{z}$. We demonstrate in Rose and Spiegel (2011) that $y_{z}$ does not enter into the first order conditions. This is the mechanism through which the degenerate portfolio solutions are recovered each time the agents return to the centralized market in the Lagos and Wright (2005) framework. There are also four asset market clearing conditions, as the representative agent from each country holds his country's share of each asset.

In the decentralized market, agents are randomly paired into bilateral meetings. Let $z$ and $k$ represent the countries of origin of the buyer and seller respectively in the decentralized market $(z, k=u, r)$. To allow for international liquidity differences we assume that sellers in the decentralized market only accept assets denominated in their domestic currencies. The probability of landing in a meeting in which there is a coincidence of wants is exogenous, but is proportional to the share of output of country $k, \tau_{k}$, and is greater among agents originating from the same country by an exogenous parameter $\alpha>1$. Let $\lambda_{z, k}$ represent the probability that an agent from $z$ is paired with an agent from $k$ from whom he wants to buy, and $\widetilde{\lambda}_{z, k}$ represent the chance that an agent from $z$ is paired with an agent from country $k$ to whom he wants to sell. We assume that $\lambda_{z, k} \equiv \lambda \tau_{k}$ when $z \neq k$ and $\lambda_{z, k} \equiv \lambda \alpha \tau_{k}$ when $z=k$, and that $\widetilde{\lambda}_{z, k} \equiv \widetilde{\lambda} \tau_{k}$ when $z \neq k$ and $\widetilde{\lambda}_{z, k} \equiv \widetilde{\lambda} \alpha \tau_{k}$ when $z=k$, where $\lambda$ and $\widetilde{\lambda}$ are exogenous constants.

All agents from country $k$ are informed about the value of their domestic currency, but only a fraction $\rho_{k}$ are informed about the value of $a_{k}$. We label meetings where the seller is informed market [Lagos and Rocheteau (2008)]. We rule this out for simplicity 
about $a_{k}$ "type 2 ," and meetings where the seller is uninformed "type 1 ." The type of meeting that is taking place is known to all.

Consider a type $n$ meeting ( $n=1,2)$ where there is a coincidence of wants between a buyer from country $z$ and a seller from country $k$. Let $p_{z, k, n}$ represent the price paid by the buyer from country $z$ to a seller from country $k$ for $q_{z, k, n}$ units of the good, and let $y_{z}$ and $y_{k}$ represent the wealth of the buyer and the seller respectively. Finally, let $\omega_{z, k, n}$ be the value of acceptable funds possessed by the buyer, i.e. those recognized by the seller and denominated in the seller's domestic currency. Given our assumptions above, $\omega_{z, k, 1}=\phi_{k} m_{z, k}$, and $\omega_{z, k, 2}=\phi_{k} m_{z, k}+\left(\psi_{k}+\delta_{k}\right) a_{z, k}$.

Assuming that the buyer has bargaining power $\theta$ and threat points are given by continuation values, the generalized Nash bargaining solution is similar to that in Lagos and Wright (2005):

$$
\max _{q_{z, k, n}, p_{z, k, n}}\left[\left[v\left(q_{z, k, n}\right)+W\left(y_{z}-p_{z, k, n}\right)\right]-W_{z}\left(y_{z}\right)\right]^{\theta}\left[\left[-c\left(q_{z, k, n}\right)+W\left(y_{k}+p_{z, k, n}\right)\right]-W\left(y_{k}\right)\right]^{1-\theta}
$$

subject to $p_{z, k, n} \leq \omega_{z, k, n}$.

The first order conditions satisfy

$$
p_{z, k, n}=\frac{\theta v^{\prime}\left(q_{z, k, n}\right) c\left(q_{z, k, n}\right)+(1-\theta) v\left(q_{z, k, n}\right) c^{\prime}\left(q_{z, k, n}\right)}{\theta v^{\prime}\left(q_{z, k, n}\right)+(1-\theta) c^{\prime}\left(q_{z, k, n}\right)} \equiv \eta\left(q_{z, k, n}\right)
$$

and

$$
-\theta\left[-c\left(q_{z, k, n}\right)+p_{z, k, n}\right]+(1-\theta)\left[v\left(q_{z, k, n}\right)-p_{z, k, n}\right]-\varphi\left[-c\left(q_{z, k, n}\right)+p_{z, k, n}\right]^{\theta}\left[v\left(q_{z, k, n}\right)-p_{z, k, n}\right]^{(1-\theta)}=0 .
$$

We assume that the liquidity constraint is binding, which implies that $p_{z, k, n}=\omega_{z, k, n}$ and $q_{z, k, n}$ satisfies 6 for $p_{z, k, n}=\omega_{z, k, n}$. Note that the terms of trade only depend on the buyer's portfolio.

The value function of an agent from country $z$ in the decentralized market then satisfies

$$
V_{z}=\sum_{n=1}^{2}\left[\lambda_{u, n}\left[v\left(q_{z, u, n}\right)+W\left(y_{z}-p_{z, u, n}\right)\right]+\lambda_{r, n}\left[v\left(q_{z, r, n}\right)+W\left(y_{z}-p_{z, r, n}\right)\right]\right]+(1-\lambda) W\left(y_{z}\right)+\Psi_{k}
$$

where $\lambda_{k, 1}=\lambda_{k}\left(1-\rho_{k}\right), \lambda_{k, 2}=\lambda_{k} \rho_{k}$, and $\Psi_{k}$ represents the extra utility of an agent from country $k$ associated with being a seller relative to having no trade opportunities.

Let $\widetilde{q}_{z, k, n}$ and $\widetilde{p}_{z, k, n}$ represent the proceeds of selling $q$ to an agent from country $z . \Psi_{k}$ satisfies 
$\Psi_{k}=\left\{\widetilde{\lambda}_{i}\left[-c\left(\widetilde{q}_{i, k, 1}\right)+\widetilde{p}_{i, k, 1}\right]+\widetilde{\lambda}_{j}\left[-c\left(\widetilde{q}_{j, k, 1}\right)+\widetilde{p}_{j, k, 1}\right]\right\}\left(1-\Phi_{k}\right)+\left\{\widetilde{\lambda}_{i}\left[-c\left(\widetilde{q}_{i, k, 2}\right)+\widetilde{p}_{i, k, 2}\right]+\widetilde{\lambda}_{j}\left[-c\left(\widetilde{q}_{j, k, 2}\right)+\widetilde{p}_{j, k, 2}\right]\right\} \Phi_{k}$

where $\Phi_{k}$ is an indicator variable that takes value 1 if agent $k$ is informed about $a_{k}$, and 0 otherwise. It can be easily seen that $\Psi_{k}$ is invariant to the portfolio decision of the agent from country $k$.

As in Lagos and Wright (2005), let $\ell\left(q_{z, k, n}\right) \equiv\left[v^{\prime}\left(q_{z, k, n}\right) / \eta^{\prime}\left(q_{z, k, n}\right)\right]-1$ represent the liquidity premium in a type $n$ meeting with a buyer from country $z$ and a seller from country $k . \ell\left(q_{z, k, n}\right)$ is the increase in buyer utility from bringing an additional unit of country $k$ currency into a type $n$ meeting above its value in the next centralized market. We also follow Lagos and Wright (2005) in assuming that $\ell^{\prime}\left(q_{z, k, n}\right) \leq 0$, which holds under usual conditions.

Differentiating $V_{z}$ and combining the results with the centralized market solution conditions yields individual agents' demand for currencies $u$ and $r$, as well as assets $\psi_{u}$ and $\psi_{r}$. Equilibrium is defined as a solution for asset holdings, asset prices, the terms of trade in the decentralized markets, and leisure choices that satisfy the maximization conditions of each agent, the bargaining solutions in the decentralized markets, and market clearing in the centralized market. In the steady state, real variables are constant over time, and $\phi_{z}$ and $M_{z}$ grow at a constant rate $\gamma_{z}(z=u, r)$. The steady state versions of the money and asset demand equations satisfy

$$
\begin{gathered}
\frac{\gamma-\beta}{\beta \lambda_{u}} \geq\left(1-\rho_{u}\right) \ell\left(q_{z, u, 1}\right)+\rho_{u} \ell\left(q_{u, 2}\right), \\
\frac{\gamma-\beta}{\beta \lambda_{r}} \geq\left(1-\rho_{r}\right) \ell\left(q_{z, r, 1}\right)+\rho_{r} \ell\left(q_{r, 2}\right), \\
\frac{(1-\beta) \psi_{u}-\beta \delta_{u}}{\beta\left(\psi_{u}+\delta_{u}\right) \lambda_{u}}=\rho_{u} \ell\left(q_{z, u, 2}\right),
\end{gathered}
$$

and

$$
\frac{(1-\beta) \psi_{r}-\beta \delta_{r}}{\beta\left(\psi_{r}+\delta_{r}\right) \lambda_{r}}=\rho_{r} \ell\left(q_{z, r, 2}\right),
$$

where the conditions hold with equality when positive levels of money or assets are held. Existence and uniqueness of the equilibrium is demonstrated in Rose and Spiegel (2011).

We next examine the comparative static impact of a decline in $\delta_{u}$. First by equation 12 , the change in $\psi_{u}$ with a decline in $\delta_{u}$ satisfies

$$
\frac{\partial \psi_{u}}{\partial \delta_{u}}=\frac{\delta_{u}-\beta\left(\psi_{u}+\delta_{u}\right) \lambda_{u} \rho_{u} \ell^{\prime}\left(q_{z, u, 2}\right) I\left\{\omega_{z, u, 2}<\eta\left(q^{*}\right)\right\}}{\psi_{u}-\beta\left(\psi_{u}+\delta_{u}\right) \lambda_{u} \rho_{u} \ell^{\prime}\left(q_{z, u, 2}\right) I\left\{\omega_{z, u, 2}<\eta\left(q^{*}\right)\right\}} .
$$


The numerator of equation 14 is unambiguously positive, but the denominator is ambiguous in sign. The necessary condition for $\partial \psi_{u} / \partial \delta_{u} \geq 0$ is that $\ell^{\prime}\left(q_{z, u, 2}\right)$ is not "too large". We require the restriction $\psi_{u} \geq \beta\left(\psi_{u}+\delta_{u}\right) \lambda_{u} \rho_{u} \ell^{\prime}\left(q_{z, u, 2}\right) I\left\{\omega_{z, u, 2}<\eta\left(q^{*}\right)\right\}$, which implies that asset values fall with declines in their dividend streams, which we adopt.

Substituting from equation 12 into equation 10 and totally differentiating with respect to $\phi_{u} m_{z, u}$ and $\delta_{u}$ yields

$$
\frac{\partial \phi_{u} m_{z, u}}{\partial \delta_{u}}=\frac{\psi_{u}+\delta_{u} \frac{\partial \psi_{u}}{\partial \delta_{u}}}{\left(\psi_{u}+\delta_{u}\right)^{2} \beta \lambda_{u}\left(1-\rho_{u}\right) \ell^{\prime}\left(q_{z, u, 1}\right) I\left\{\widehat{\omega}_{z, u, 1}<\eta\left(q^{*}\right)\right\}} \leq 0,
$$

as $\frac{\partial \psi_{u}}{\partial \delta_{u}}$ can be signed as positive given the restriction above.

In contrast, it can be seen by inspection of equations 13 and 11 that $\psi_{r}$ and $\phi_{r} m_{z, r}$ are invariant to changes in $\delta_{u}$. This implies that a decline in $\delta_{u}$ will lead to an appreciation in country $u$ 's exchange rate, $\phi_{u} / \phi_{r}$.

A formal proof is in Rose and Spiegel (2011). Intuitively, as $m_{z, u}$ is exogenous, any change in real balances, $\phi_{u} m_{z, u}$ must come from an increase in $\phi_{u}$. In contrast, since $\phi_{r} m_{z, r}$ is unchanged $\phi_{r}$ must be unchanged as well.

We next turn to our empirical work by assessing the implications of our model for the predicted impact of the U.S. dollar auctions by foreign central banks. We assume that dollar injections are surprise interventions that take place in the decentralized market subsequent to the fall in $\delta_{u}$. As was the case empirically, the dollar injections are assumed to be loans which for tractability we assume are repaid in the next entry into the centralized market.

The impact of the liquidity injection can then be represented in terms of the change in the decentralized market value function with an increase in US currency holdings. The influence of country characteristics on the relative impact of the injections can then be shown in terms of the cross-partials of the decentralized market value function with respect to dollar holdings and these characteristics. We examine three: $\lambda_{r, u}, \rho_{u}$, and $\ell\left(q_{r, u, 1}\right)$. By equation $8, \partial^{2} V_{r} / \partial m_{r, u} \partial \lambda_{r, u}$, $\partial^{2} V_{r} / \partial m_{r, u} \partial \rho_{u}$ and $\partial^{2} V_{r} / \partial m_{r, u} \partial \ell\left(q_{r, u, 1}\right)$ satisfy

$$
\begin{gathered}
\frac{\partial^{2} V_{r}}{\partial m_{r, u} \partial \lambda_{r, u}}=\phi_{u}\left[\left(1-\rho_{u}\right) \ell\left(q_{r, u, 1}\right) I_{r, u, 1}+\rho_{u} \ell\left(q_{r, u, 2}\right) I_{r, u, 2}\right] \geq 0, \\
\frac{\partial^{2} V_{r}}{\partial m_{r, u} \partial \rho_{u}}=\phi_{u} \lambda_{r, u}\left[-\ell\left(q_{r, u, 1}\right) I_{r, u, 1}+\ell\left(q_{r, u, 2}\right) I_{r, u, 2}\right]<0,
\end{gathered}
$$

and

$$
\frac{\partial^{2} V_{r}}{\partial m_{r, u} \partial \ell\left(q_{r, u, 1}\right)}=\theta_{u} \lambda_{r, u, 1} I_{r, u, 1}>0
$$


Figure 1: Stock Market Volatility and Bilateral Exchange Rate

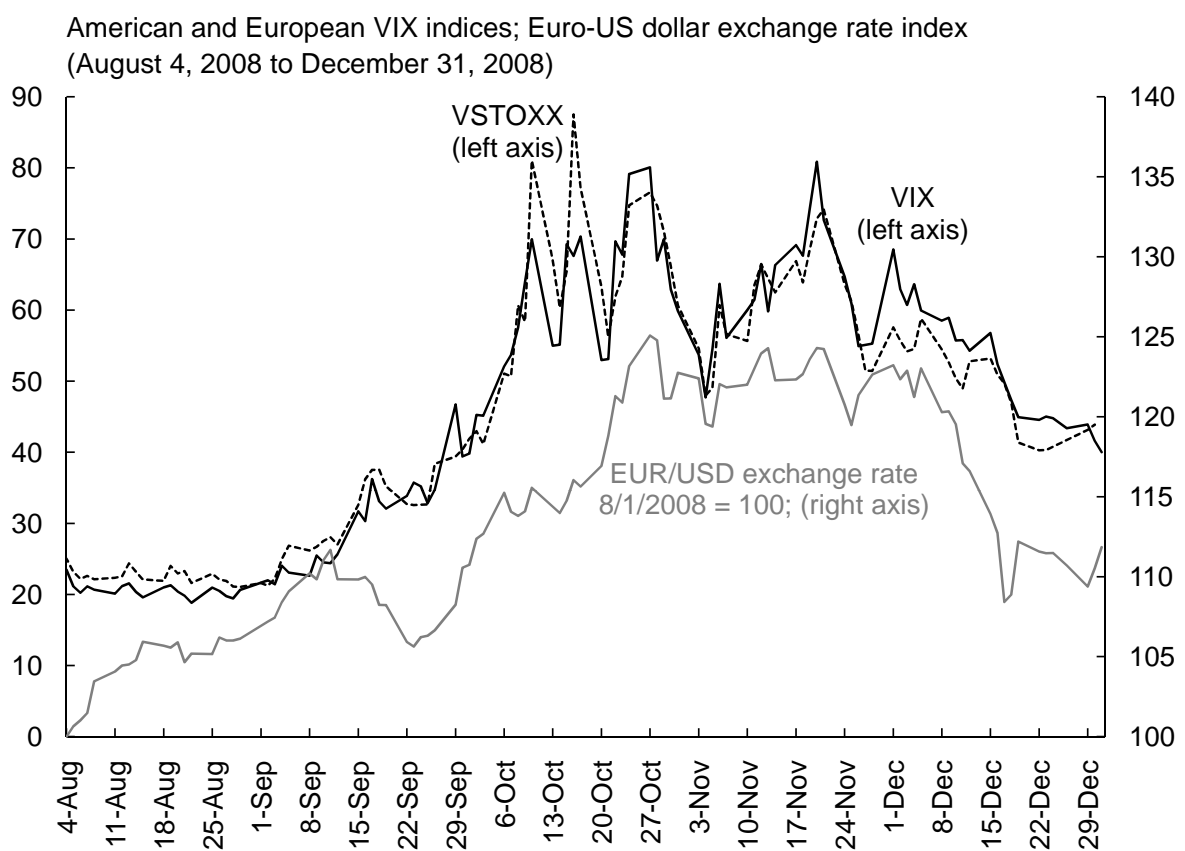

Sources: Bloomberg and Federal Reserve DistFAME

VIX and VSTOXX indicies of equity market volatility in United States and European exchanges respectively. Daily frequency.

Dollar-euro exchange rate indexed to 100 on August 1, 2008. 
Figure 2: Weekly Major Central Bank TAF Auction Volumes

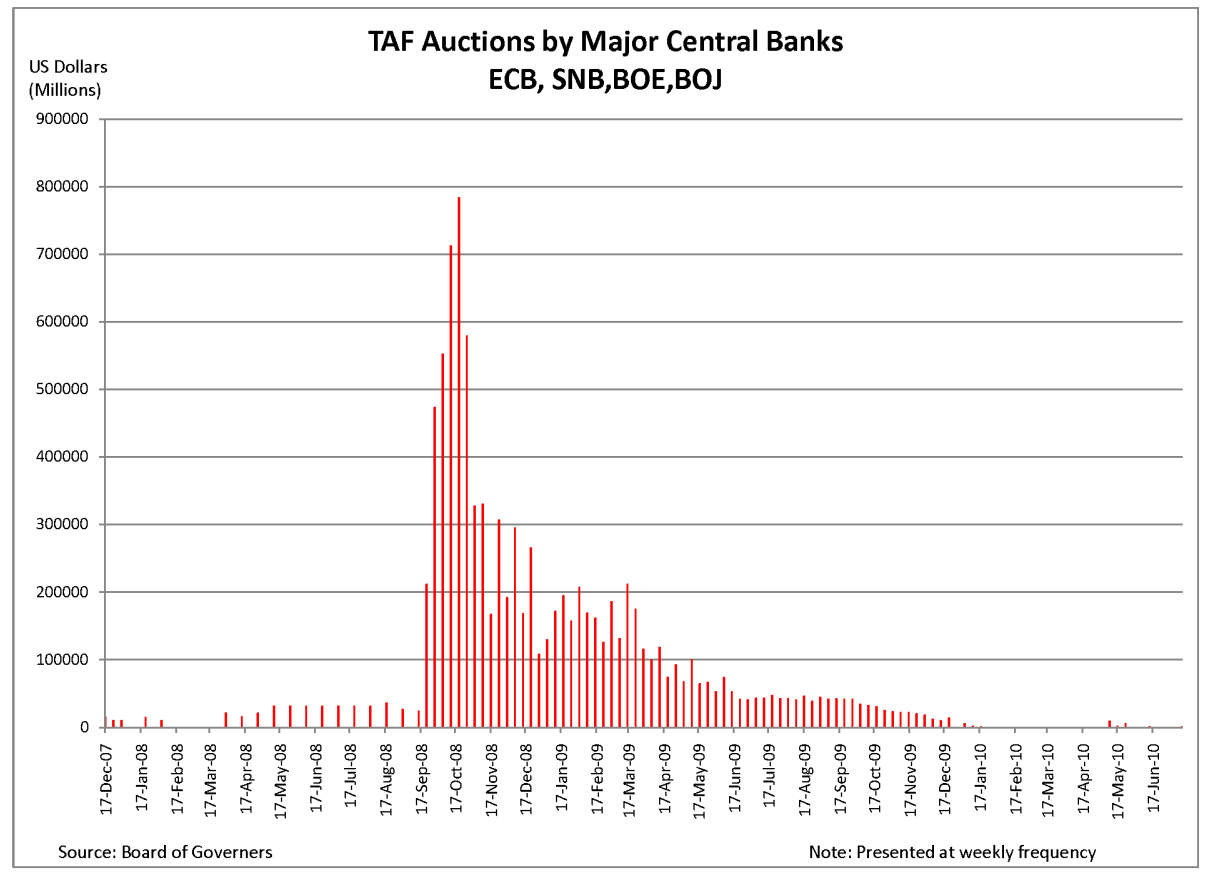

Source: Board of Governors

Total weekly volume of TAF auctions by major central banks. 

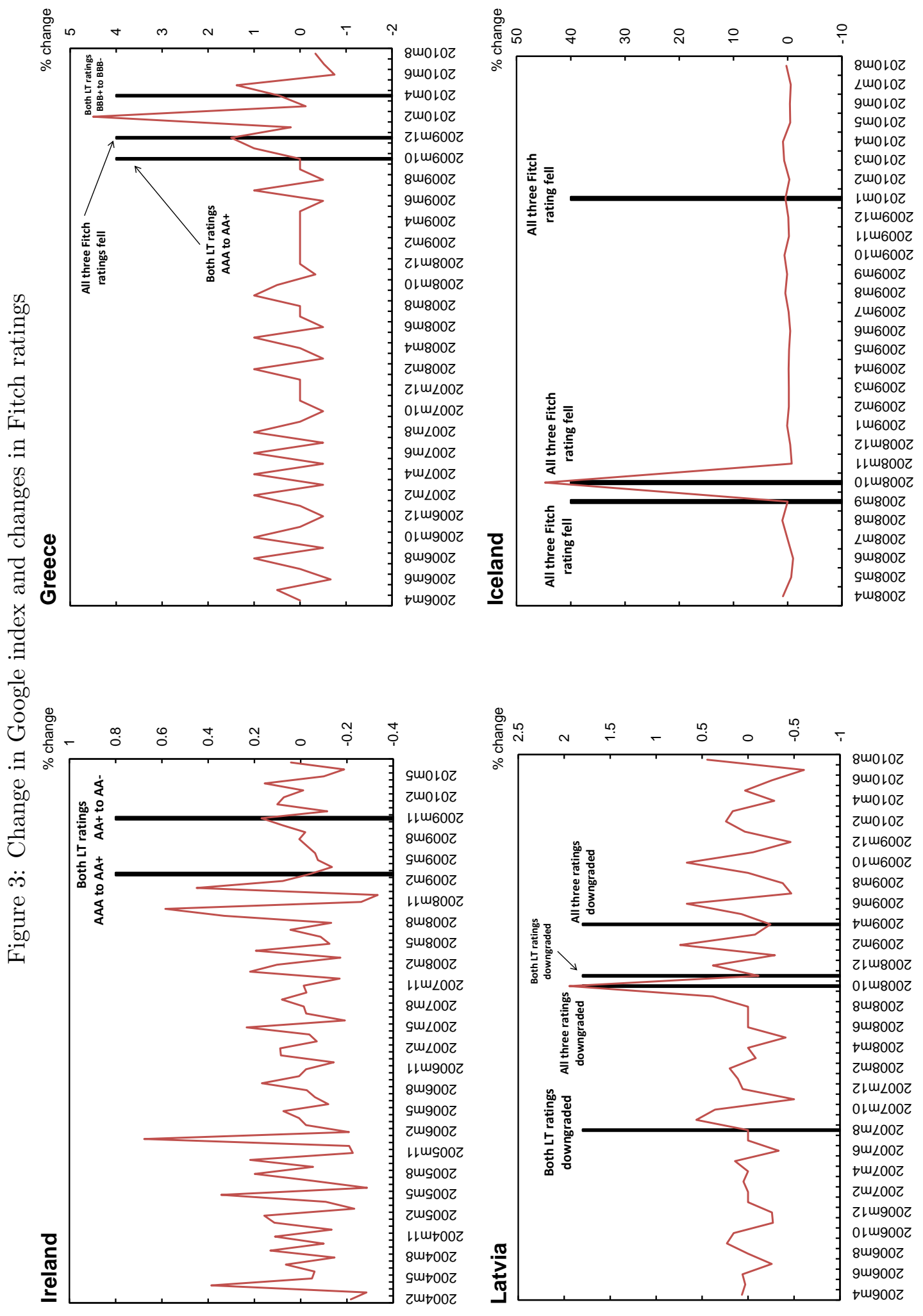

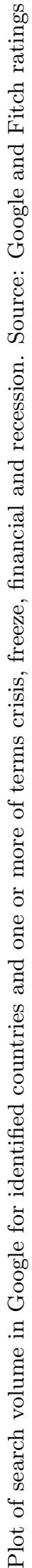


Table 1: Announcements concerning international swap arrangements: 2007-2008

\begin{tabular}{|c|c|c|}
\hline Announcement Type & Date & Details \\
\hline $\begin{array}{l}\text { Swap lines introduced with ECB } \\
\text { and SNB }\end{array}$ & $12 / 12 / 2007$ & $\begin{array}{l}\text { Authorization of temporary reciprocal currency arrangements with the European Central } \\
\text { Bank and Swiss National Bank, providing } \$ 20 \text { billion and } \$ 4 \text { billion } \\
\text { respectively.Arrangements authorized for up to six months. }\end{array}$ \\
\hline $\begin{array}{l}\text { Swap lines introduced with BOJ, } \\
\text { BOE, and Bank of Canada. Funds } \\
\text { increased for the ECB and SNB. }\end{array}$ & $9 / 18 / 2008$ & $\begin{array}{l}\text { New swap facilities authorized with the Bank of Japan for amounts up to } \$ 60 \text { billion, the } \\
\text { Bank of England for up to } \$ 40 \text { billion, and the Bank of Canada for up to } \$ 10 \text { billion. In } \\
\text { addition, swap line provisions increased to } \$ 110 \text { for the European Central Bank and } \$ 27 \\
\text { billion to the Swiss National Bank. Arrangements authorized through January 30,2009 }\end{array}$ \\
\hline $\begin{array}{l}\text { Swap lines introduced with } \\
\text { Australia, Sweden, Denmark, and } \\
\text { Norway. }\end{array}$ & $9 / 24 / 2008$ & $\begin{array}{l}\text { Currency swap facilities established in amounts of up to } \$ 10 \text { billion each by the Reserve } \\
\text { Bank of Australia and Sveriges Riksbank and amounts of up to } \$ 5 \text { billion each by Danmarks } \\
\text { Nationalbank and the Norges Bank. Arrangements authorized through January 30,2009 }\end{array}$ \\
\hline $\begin{array}{l}\text { Unlimited swaps announced with } \\
\qquad \mathrm{ECB}, \mathrm{BOE} \text {, and SNB. }\end{array}$ & $10 / 13 / 2008$ & $\begin{array}{l}\text { Funds provided to swap facilities with the Bank of England, the European Central Bank, and } \\
\text { the Swiss National Bank increased to "accommodate whatever quantity of U.S. dollar } \\
\text { funding is demanded". Arrangements were authorized through April 30,2009. }\end{array}$ \\
\hline $\begin{array}{l}\text { Unlimited Swaps announced with } \\
\text { the BOJ }\end{array}$ & $10 / 14 / 2008$ & $\begin{array}{l}\text { Unlimited swap arrangement announced with the Bank of Japan a day after the same } \\
\text { announcement was made regarding swap lines with major central bank in Europe. } \\
\text { Arrangements authorized though April 30,2009 }\end{array}$ \\
\hline $\begin{array}{l}\text { Swap lines introduced with the } \\
\text { Reserve Bank of New Zealand }\end{array}$ & $10 / 28 / 2008$ & $\begin{array}{l}\text { New swap line of up to } \$ 15 \text { billion with the Reserve Bank of New Zealand announced. } \\
\text { Arrangement authorized through April 30, } 2009 \text {. }\end{array}$ \\
\hline $\begin{array}{l}\text { Swap Line Introduced with Brazil, } \\
\text { Mexico, Korea, and Singapore. }\end{array}$ & $10 / 29 / 2008$ & $\begin{array}{l}\text { New swap facilities established in amounts of up to } \$ 30 \text { billion each by the Banco Central } \\
\text { do Brazo, the Banco de Mexico, the Bank of Korea, and the Monetary Authority of } \\
\text { Singapore. Authorized through April 30, } 2009 \text {. }\end{array}$ \\
\hline
\end{tabular}

Source: Federal Reserve Board of Governors 
Table 2: TAF Auctions by major central banks

\begin{tabular}{||c||c|c||c|c||c|c||c|c||}
\hline \hline & \multicolumn{2}{|c|}{ ECB } & \multicolumn{2}{c||}{ BOE } & \multicolumn{2}{c||}{ BOJ } & \multicolumn{2}{c||}{ SNB } \\
\hline Quarter & $\begin{array}{c}\text { Dollars } \\
\text { Auctioned } \\
\text { (Millions) }\end{array}$ & $\begin{array}{c}\text { Average } \\
\text { Tenor } \\
\text { (Days) }\end{array}$ & $\begin{array}{c}\text { Dollars } \\
\text { Auctioned } \\
\text { (Millions) }\end{array}$ & $\begin{array}{c}\text { Average } \\
\text { Tenor } \\
\text { (Days) }\end{array}$ & $\begin{array}{c}\text { Dollars } \\
\text { Auctioned } \\
\text { (Millions) }\end{array}$ & $\begin{array}{c}\text { Average } \\
\text { Tenor } \\
\text { (Days) }\end{array}$ & $\begin{array}{c}\text { Dollars } \\
\text { Auctioned } \\
\text { (Millions) })\end{array}$ & $\begin{array}{c}\text { Average } \\
\text { Tenor } \\
\text { (Days) }\end{array}$ \\
\hline 2007q4 & 20000 & 31.5 & - & - & - & - & 4000 & 28.0 \\
\hline 2008q1 & 35000 & 28.0 & - & - & - & - & 10000 & 28.0 \\
\hline $2008 q 2$ & 130000 & 28.0 & - & - & - & - & 30000 & 28.0 \\
\hline $2008 q 3$ & 589742 & 11.3 & 216044 & 2.1 & 29622 & 28.0 & 132139 & 11.8 \\
\hline $2008 q 4$ & 3608841 & 8.3 & 667737 & 9.7 & 205635 & 54.2 & 196948 & 11.3 \\
\hline $2009 q 1$ & 1937722 & 7.4 & 30956 & 50.6 & 106253 & 59.1 & 51702 & 20.0 \\
\hline $2009 q 2$ & 865642 & 9.5 & 3503 & 59.7 & 36243 & 49.4 & 41006 & 18.7 \\
\hline $2009 q 3$ & 542729 & 7.5 & 538 & 26.4 & 8100 & 31.5 & 18 & 28.0 \\
\hline 2009q4 & 259478 & 7.5 & 52 & 7.0 & 1300 & 32.4 & - & - \\
\hline $2010 q 1$ & 6575 & 7.0 & - & - & 100 & 29.0 & - & - \\
\hline
\end{tabular}

Source: Federal Reserve Board of Governors

Notes: Size (millions of dollars) and average tenor (days) of dollar auctions by major central banks. 
Table 3: Google searches and sovereign ratings

I. Full Sample: January 2004-September 2010

\begin{tabular}{|c|c|c|c|c|c|}
\hline Rating & Coefficient & T-stat & \# of Obs & \# of Countries & R-squared \\
\hline Local LT & $-0.04^{* *}$ & -4.0 & 5360 & 100 & 0.07 \\
\hline Foreign LT & $-0.01^{* *}$ & -5.15 & 5410 & 99 & 0.04 \\
\hline Foreign ST & $-0.05^{* *}$ & -4.73 & 5363 & 98 & 0.09 \\
\hline
\end{tabular}

II. Study Sample: December 2007-December 2009

\begin{tabular}{|c|c|c|c|c|c|}
\hline Rating & Coefficient & T-stat & \# of Obs & \# of Countries & R-squared \\
\hline Local LT & $-0.04^{* *}$ & -9.7 & 2245 & 96 & 0.15 \\
\hline Foreign LT & $-0.02^{* *}$ & -11.56 & 2270 & 96 & 0.08 \\
\hline Foreign ST & $-0.06^{* *}$ & -10.81 & 2260 & 96 & 0.22 \\
\hline
\end{tabular}

Regression of Fitch Ratings changes on changes in Google Index

Source: Google Insight for Search, Fitch

OLS panel estimation with country and time fixed effects included.

Monthly data with robust standard errors. 
Table 4: Base specification

\begin{tabular}{lccccccc}
\hline \hline & $(1)$ & $(2)$ & $(3)$ & $(4)$ & $(5)$ & $(6)$ & $(7)$ \\
& Exports & Imports & Trade & Assets(TIC) & Assets(CPIS) & Debt & LTdebt \\
\hline Exposure*auction & $-2.87^{*}$ & $-2.56^{* *}$ & $-3.14^{* *}$ & $-0.64^{* *}$ & -0.01 & $-0.66^{* *}$ & $-0.68^{* *}$ \\
& $(-2.15)$ & $(-4.94)$ & $(-2.95)$ & $(-3.99)$ & $(-1.42)$ & $(-3.50)$ & $(-3.62)$ \\
Transp*auction & $-0.58^{*}$ & $-0.61^{*}$ & $-0.54^{*}$ & $-0.58^{*}$ & $-0.54^{*}$ & $-0.74^{* *}$ & $-0.75^{* *}$ \\
& $(-2.10)$ & $(-2.65)$ & $(-2.14)$ & $(-2.43)$ & $(-2.19)$ & $(-3.26)$ & $(-3.27)$ \\
Illiquid*auction & 1.64 & 0.68 & 0.81 & 0.94 & 0.51 & 0.89 & 0.94 \\
& $(1.04)$ & $(1.25)$ & $(1.22)$ & $(1.80)$ & $(0.66)$ & $(1.46)$ & $(1.53)$ \\
Exposure*SP500 & $-6.97^{* *}$ & $-6.05^{* *}$ & $-8.16^{* *}$ & $-1.85^{* *}$ & $-0.03^{* *}$ & $-2.00^{* *}$ & $-1.98^{* *}$ \\
& $(-5.20)$ & $(-4.58)$ & $(-6.20)$ & $(-21.05)$ & $(-4.87)$ & $(-15.37)$ & $(-14.61)$ \\
$\Delta$ Default & 0.36 & 0.48 & 0.28 & 0.61 & $1.51^{*}$ & 0.66 & 0.67 \\
& $(0.52)$ & $(0.76)$ & $(0.43)$ & $(0.85)$ & $(2.11)$ & $(0.91)$ & $(0.93)$ \\
\hline Num of Obs & 4005 & 4005 & 4005 & 4005 & 3607 & 4005 & 4005 \\
$R^{2}$ & 0.200 & 0.200 & 0.212 & 0.240 & 0.209 & 0.217 & 0.216 \\
\hline \hline
\end{tabular}

$\mathrm{t}$ statistic in parentheses; OLS with country fixed effects, monthly time dummies, and robust standard errors.

${ }^{*} p<0.05,{ }^{* *} p<0.01$ 
Table 5: Alternative illiquidity measures

\begin{tabular}{|c|c|c|c|c|c|c|c|}
\hline & $\begin{array}{c}(1) \\
\text { Exports }\end{array}$ & $\begin{array}{c}(2) \\
\text { Imports }\end{array}$ & $\begin{array}{c}(3) \\
\text { Trade }\end{array}$ & $\begin{array}{c}(4) \\
\text { Assets(TIC) }\end{array}$ & $\begin{array}{c}(5) \\
\text { Assets(CPIS) }\end{array}$ & $\begin{array}{c}(6) \\
\text { Debt }\end{array}$ & $\begin{array}{c}(7) \\
\text { LTdebt }\end{array}$ \\
\hline \multicolumn{8}{|c|}{ I. Illiquidity proxied by ST Debt/GDP } \\
\hline Exposure*auction & $\begin{array}{l}-2.66^{*} \\
(-2.42)\end{array}$ & $\begin{array}{l}-2.57^{* *} \\
(-4.90)\end{array}$ & $\begin{array}{l}-3.19^{* *} \\
(-2.88)\end{array}$ & $\begin{array}{l}-0.63^{* *} \\
(-3.96)\end{array}$ & $\begin{array}{l}-0.01 \\
(-1.45)\end{array}$ & $\begin{array}{l}-0.64^{* *} \\
(-3.55)\end{array}$ & $\begin{array}{l}-0.66^{* *} \\
(-3.66)\end{array}$ \\
\hline Transp*auction & $\begin{array}{l}-0.57^{*} \\
(-2.08)\end{array}$ & $\begin{array}{l}-0.59^{*} \\
(-2.62)\end{array}$ & $\begin{array}{l}-0.52^{*} \\
(-2.06)\end{array}$ & $\begin{array}{l}-0.56^{*} \\
(-2.39)\end{array}$ & $\begin{array}{l}-0.53^{*} \\
(-2.14)\end{array}$ & $\begin{array}{l}-0.72^{* *} \\
(-3.24)\end{array}$ & $\begin{array}{l}-0.72^{* *} \\
(-3.25)\end{array}$ \\
\hline ill_gdp*auction & $\begin{array}{c}0.59 \\
(1.16)\end{array}$ & $\begin{array}{c}0.32 \\
(1.20)\end{array}$ & $\begin{array}{c}0.56 \\
(1.46)\end{array}$ & $\begin{array}{c}0.35 \\
(1.14)\end{array}$ & $\begin{array}{c}0.32 \\
(0.91)\end{array}$ & $\begin{array}{c}0.26 \\
(1.00)\end{array}$ & $\begin{array}{c}0.23 \\
(0.88)\end{array}$ \\
\hline \multicolumn{8}{|c|}{ II. Illiquidity proxied by ST Debt/Reserves } \\
\hline Exposure*auction & $\begin{array}{l}-2.60^{*} \\
(-2.51)\end{array}$ & $\begin{array}{l}-2.55^{* *} \\
(-4.94)\end{array}$ & $\begin{array}{l}-3.14^{* *} \\
(-2.92)\end{array}$ & $\begin{array}{l}-0.62^{* *} \\
(-3.91)\end{array}$ & $\begin{array}{c}-0.01 \\
(-1.46)\end{array}$ & $\begin{array}{l}-0.64^{* *} \\
(-3.52)\end{array}$ & $\begin{array}{l}-0.66^{* *} \\
(-3.63)\end{array}$ \\
\hline Transp*auction & $\begin{array}{l}-0.58^{*} \\
(-2.12)\end{array}$ & $\begin{array}{l}-0.59^{*} \\
(-2.66)\end{array}$ & $\begin{array}{l}-0.53^{*} \\
(-2.09)\end{array}$ & $\begin{array}{l}-0.57^{*} \\
(-2.42)\end{array}$ & $\begin{array}{l}-0.54^{*} \\
(-2.18)\end{array}$ & $\begin{array}{l}-0.73^{* *} \\
(-3.27)\end{array}$ & $\begin{array}{l}-0.73^{* *} \\
(-3.28)\end{array}$ \\
\hline ill_res*auction & $\begin{array}{c}0.09 \\
(0.85)\end{array}$ & $\begin{array}{c}0.02 \\
(0.22)\end{array}$ & $\begin{array}{c}0.09 \\
(0.95)\end{array}$ & $\begin{array}{c}0.00 \\
(0.02)\end{array}$ & $\begin{array}{c}0.04 \\
(0.44)\end{array}$ & $\begin{array}{l}-0.00 \\
(-0.02)\end{array}$ & $\begin{array}{c}-0.01 \\
(-0.12)\end{array}$ \\
\hline III. Illiquidity prox & ed by $\mathrm{Gr}$ & enspan-G & idotti me & ure & & & \\
\hline Exposure*auction & $\begin{array}{l}-2.18^{*} \\
(-2.13)\end{array}$ & $\begin{array}{l}-2.09^{* *} \\
(-4.04)\end{array}$ & $\begin{array}{l}-2.49^{*} \\
(-2.23)\end{array}$ & $\begin{array}{l}-0.44^{*} \\
(-2.16)\end{array}$ & $\begin{array}{c}-0.01 \\
(-1.03)\end{array}$ & $\begin{array}{c}-0.35 \\
(-1.19)\end{array}$ & $\begin{array}{c}-0.39 \\
(-1.40)\end{array}$ \\
\hline Transp*auction & $\begin{array}{c}-0.18 \\
(-0.57)\end{array}$ & $\begin{array}{c}-0.24 \\
(-0.74)\end{array}$ & $\begin{array}{c}-0.20 \\
(-0.65)\end{array}$ & $\begin{array}{c}-0.26 \\
(-0.72)\end{array}$ & $\begin{array}{c}-0.18 \\
(-0.51)\end{array}$ & $\begin{array}{c}-0.20 \\
(-0.43)\end{array}$ & $\begin{array}{c}-0.24 \\
(-0.54)\end{array}$ \\
\hline ill_GG*auction & $\begin{array}{c}0.32 \\
(1.75)\end{array}$ & $\begin{array}{c}0.30 \\
(1.51)\end{array}$ & $\begin{array}{c}0.29 \\
(1.51)\end{array}$ & $\begin{array}{c}0.28 \\
(1.14)\end{array}$ & $\begin{array}{c}0.31 \\
(1.46)\end{array}$ & $\begin{array}{c}0.40 \\
(1.27)\end{array}$ & $\begin{array}{c}0.37 \\
(1.23)\end{array}$ \\
\hline
\end{tabular}

Coefficients for ill_gdp are presented in millions

$\mathrm{t}$ statistic in parentheses; OLS with country fixed effects, monthly time dummies, and robust standard errors.

${ }^{*} p<0.05,{ }^{* *} p<0.01$ 
Table 6: OECD countries only

\begin{tabular}{lccccccc}
\hline \hline & $(1)$ & $(2)$ & $(3)$ & $(4)$ & $(5)$ & $(6)$ & $(7)$ \\
& Exports & Imports & Trade & Assets(TIC) & Assets(CPIS) & Debt & LTdebt \\
\hline Exposure*auction & $-6.53^{*}$ & $-2.42^{* *}$ & $-4.87^{* *}$ & $-0.96^{* *}$ & $-0.01^{*}$ & $-1.00^{* *}$ & $-0.93^{* *}$ \\
& $(-2.76)$ & $(-3.19)$ & $(-3.44)$ & $(-3.63)$ & $(-2.08)$ & $(-4.09)$ & $(-3.83)$ \\
Transp*auction & -0.01 & -0.22 & -0.05 & -0.12 & -0.07 & -0.31 & -0.33 \\
& $(-0.04)$ & $(-0.75)$ & $(-0.16)$ & $(-0.48)$ & $(-0.33)$ & $(-1.12)$ & $(-1.18)$ \\
Illiquid*auction & 5.20 & 1.14 & $3.45^{*}$ & 1.45 & 1.55 & 0.76 & 0.50 \\
& $(2.02)$ & $(1.05)$ & $(2.43)$ & $(1.60)$ & $(1.15)$ & $(0.77)$ & $(0.49)$ \\
Exposure*SP500 & $-10.98^{* *}$ & $-4.79^{* *}$ & $-8.75^{* *}$ & $-2.05^{* *}$ & $-0.04^{* *}$ & $-2.32^{* *}$ & $-2.08^{* *}$ \\
& $(-5.07)$ & $(-3.72)$ & $(-5.78)$ & $(-8.34)$ & $(-5.58)$ & $(-5.37)$ & $(-4.91)$ \\
$\Delta$ Default & $2.60^{* *}$ & $2.56^{* *}$ & $2.53^{* *}$ & $2.93^{* *}$ & $2.66^{* *}$ & $2.79^{* *}$ & $2.80^{* *}$ \\
& $(4.00)$ & $(4.15)$ & $(4.04)$ & $(5.06)$ & $(4.31)$ & $(4.58)$ & $(4.59)$ \\
\hline Num of Obs & 2220 & 2220 & 2220 & 2220 & 2220 & 2220 & 2220 \\
$R^{2}$ & 0.188 & 0.184 & 0.195 & 0.197 & 0.200 & 0.186 & 0.182 \\
\hline \hline
\end{tabular}

t statistic in parentheses; OLS with country fixed effects, monthly time dummies, and robust standard errors.

${ }^{*} p<0.05,{ }^{* *} p<0.01$ 
Table 7a: Swap announcements with major central banks

\begin{tabular}{|c|c|c|c|c|c|c|c|}
\hline & $\begin{array}{c}(1) \\
\text { Exports }\end{array}$ & $\begin{array}{c}(2) \\
\text { Imports }\end{array}$ & $\begin{array}{c}(3) \\
\text { Trade }\end{array}$ & $\begin{array}{c}(4) \\
\text { Assets(TIC) }\end{array}$ & $\begin{array}{c}(5) \\
\text { Assets(CPIS) }\end{array}$ & $\begin{array}{c}(6) \\
\text { Debt }\end{array}$ & $\begin{array}{c}(7) \\
\text { LTdebt }\end{array}$ \\
\hline \multicolumn{8}{|c|}{ I. Dec 12 '07: Lines introduced with ECB and SNB } \\
\hline Exposure & $\begin{array}{l}-14.76 \\
(-1.62)\end{array}$ & $\begin{array}{c}5.18 \\
(0.66)\end{array}$ & $\begin{array}{c}-3.48 \\
(-0.37)\end{array}$ & $\begin{array}{l}-2.69 \\
(-0.87)\end{array}$ & $\begin{array}{c}0.01 \\
(0.25)\end{array}$ & $\begin{array}{c}-0.56 \\
(-0.19)\end{array}$ & $\begin{array}{c}-0.91 \\
(-0.30)\end{array}$ \\
\hline Transp & $\begin{array}{c}18.21^{* *} \\
(3.33)\end{array}$ & $\begin{array}{c}14.85^{* *} \\
(2.85)\end{array}$ & $\begin{array}{c}15.46^{* *} \\
(2.89)\end{array}$ & $\begin{array}{c}17.52^{* *} \\
(3.30)\end{array}$ & $\begin{array}{l}14.30^{*} \\
(2.56)\end{array}$ & $\begin{array}{c}17.83^{* *} \\
(3.47)\end{array}$ & $\begin{array}{c}18.14^{* *} \\
(3.49)\end{array}$ \\
\hline Illiquid & $\begin{array}{l}-33.20 \\
(-1.52)\end{array}$ & $\begin{array}{l}-22.12^{*} \\
(-2.02)\end{array}$ & $\begin{array}{l}-23.45 \\
(-1.91)\end{array}$ & $\begin{array}{l}-27.81 \\
(-1.49)\end{array}$ & $\begin{array}{c}-30.93^{* *} \\
(-3.05)\end{array}$ & $\begin{array}{l}-41.52^{*} \\
(-2.60)\end{array}$ & $\begin{array}{l}-39.76^{*} \\
(-2.39)\end{array}$ \\
\hline \multicolumn{8}{|c|}{ II. Sep 18 '08: Lines introduced with BOJ, BOE, and Bank of Canada } \\
\hline Exposure & $\begin{array}{c}-3.40 \\
(-0.10)\end{array}$ & $\begin{array}{l}-25.09 \\
(-1.36)\end{array}$ & $\begin{array}{l}-18.37 \\
(-0.61)\end{array}$ & $\begin{array}{l}-8.66 \\
(-1.74)\end{array}$ & $\begin{array}{c}-0.12 \\
(-1.06)\end{array}$ & $\begin{array}{c}-7.65 \\
(-1.29)\end{array}$ & $\begin{array}{c}-8.33 \\
(-1.41)\end{array}$ \\
\hline Transp & $\begin{array}{l}-14.05^{*} \\
(-2.34)\end{array}$ & $\begin{array}{c}-11.44^{*} \\
(-2.12)\end{array}$ & $\begin{array}{l}-11.02 \\
(-1.92)\end{array}$ & $\begin{array}{c}-6.54 \\
(-0.99)\end{array}$ & $\begin{array}{c}-9.07 \\
(-1.40)\end{array}$ & $\begin{array}{l}-10.62 \\
(-1.78)\end{array}$ & $\begin{array}{l}-10.72 \\
(-1.81)\end{array}$ \\
\hline Illiquid & $\begin{array}{l}-50.36 \\
(-0.91)\end{array}$ & $\begin{array}{l}-55.20 \\
(-1.76)\end{array}$ & $\begin{array}{l}-51.05 \\
(-1.62)\end{array}$ & $\begin{array}{l}-24.06 \\
(-0.59)\end{array}$ & $\begin{array}{l}-35.95 \\
(-0.94)\end{array}$ & $\begin{array}{l}-19.98 \\
(-0.43)\end{array}$ & $\begin{array}{l}-18.84 \\
(-0.39)\end{array}$ \\
\hline \multicolumn{8}{|c|}{ III. Oct 13 '08:Unlimited swaps with ECB, BOE, BOJ, and SNB } \\
\hline Exposure & $\begin{array}{c}-85.29^{* *} \\
(-4.50)\end{array}$ & $\begin{array}{c}-80.45^{* *} \\
(-5.04)\end{array}$ & $\begin{array}{c}-102.39^{* *} \\
(-5.56)\end{array}$ & $\begin{array}{l}-14.05^{*} \\
(-2.22)\end{array}$ & $\begin{array}{c}-0.05 \\
(-0.13)\end{array}$ & $\begin{array}{l}-17.45^{*} \\
(-2.51)\end{array}$ & $\begin{array}{l}-17.99^{*} \\
(-2.64)\end{array}$ \\
\hline Transp & $\begin{array}{c}-25.29^{* *} \\
(-3.15)\end{array}$ & $\begin{array}{c}-24.10^{* *} \\
(-3.13)\end{array}$ & $\begin{array}{c}-21.22^{* *} \\
(-2.70)\end{array}$ & $\begin{array}{c}-31.06^{* *} \\
(-3.84)\end{array}$ & $\begin{array}{c}-30.52^{*} \\
(-2.57)\end{array}$ & $\begin{array}{c}-37.98^{* *} \\
(-4.89)\end{array}$ & $\begin{array}{c}-38.17^{* *} \\
(-4.92)\end{array}$ \\
\hline Illiquid & $\begin{array}{l}65.14 \\
(1.76)\end{array}$ & $\begin{array}{l}-51.83 \\
(-1.65)\end{array}$ & $\begin{array}{l}-25.54 \\
(-0.60)\end{array}$ & $\begin{array}{l}-36.31 \\
(-1.30)\end{array}$ & $\begin{array}{l}-71.59 \\
(-1.08)\end{array}$ & $\begin{array}{l}-16.50 \\
(-0.47)\end{array}$ & $\begin{array}{l}-16.55 \\
(-0.46)\end{array}$ \\
\hline Num of Obs & 4000 & 4000 & 4000 & 4000 & 3601 & 4000 & 4000 \\
\hline$R^{2}$ & 0.309 & 0.313 & 0.319 & 0.356 & 0.318 & 0.343 & 0.343 \\
\hline
\end{tabular}

$t$ statistics in parentheses

t statistic in parentheses; OLS with country fixed effects, monthly time dummies, and robust standard errors.

Major central banks include: European Central Bank, Swiss National Bank, Bank of Japan, Bank of England, and Bank of Canada.

${ }^{*} p<0.05,{ }^{* *} p<0.01$ 48 
Table 7b: Swap announcements with other central banks

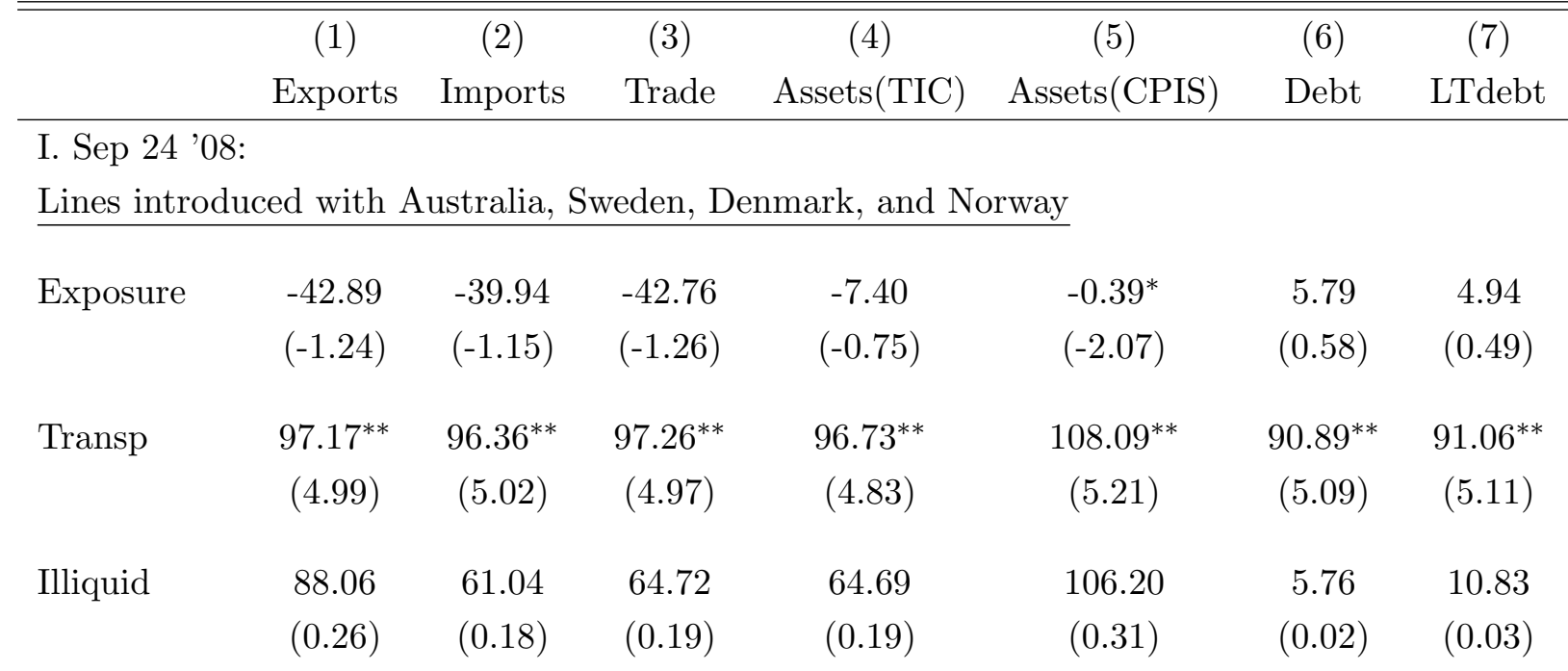

II. Oct 28 '08:

Lines introduced with New Zealand, Brazil, Mexico, South Korea, and Singapore

\begin{tabular}{lccccccc} 
Exposure & -73.09 & $-74.99^{* *}$ & $-94.30^{* *}$ & $-44.46^{* *}$ & -0.29 & $-46.21^{* *}$ & $-46.03^{* *}$ \\
& $(-1.62)$ & $(-3.54)$ & $(-2.85)$ & $(-8.11)$ & $(-1.10)$ & $(-6.79)$ & $(-6.69)$ \\
\multirow{2}{*}{ Transp } & $-71.79^{* *}$ & $-69.06^{* *}$ & $-63.61^{* *}$ & $-50.05^{* *}$ & $-60.96^{* *}$ & $-75.93^{* *}$ & $-76.98^{* *}$ \\
& $(-6.44)$ & $(-6.18)$ & $(-5.94)$ & $(-7.43)$ & $(-4.23)$ & $(-8.54)$ & $(-8.72)$ \\
\multirow{2}{*}{ Illiquid } & 67.53 & $-133.56^{*}$ & -85.45 & 34.15 & -75.38 & 81.06 & 71.73 \\
& $(0.52)$ & $(-2.09)$ & $(-1.24)$ & $(0.52)$ & $(-0.86)$ & $(0.85)$ & $(0.69)$ \\
\hline Num of Obs & 4000 & 4000 & 4000 & 4000 & 3601 & 4000 & 4000 \\
$R^{2}$ & 0.309 & 0.313 & 0.319 & 0.356 & 0.318 & 0.343 & 0.343 \\
\hline \hline
\end{tabular}

t statistic in parentheses; OLS with country fixed effects, monthly time dummies, and robust standard errors.

Other central banks include: Reserve Bank of Australia, Danmarks Nationalbank,

Bank of Korea, Bank of Mexico, Norges Bank, Sveriges Riksbank.

${ }^{*} p<0.05,{ }^{* *} p<0.01$ 
Table 8: Slope dummies for direct auction fund recipients

\begin{tabular}{|c|c|c|c|c|c|c|c|}
\hline & $\begin{array}{c}(1) \\
\text { Exports }\end{array}$ & $\begin{array}{c}(2) \\
\text { Imports }\end{array}$ & $\begin{array}{c}(3) \\
\text { Trade }\end{array}$ & $\begin{array}{c}(4) \\
\operatorname{Assets}(\mathrm{TIC})\end{array}$ & $\begin{array}{c}(5) \\
\text { Assets(CPIS })\end{array}$ & $\begin{array}{c}(6) \\
\text { Debt }\end{array}$ & $\begin{array}{c}(7) \\
\text { LTdebt }\end{array}$ \\
\hline \multirow[t]{2}{*}{ direct } & 1.78 & 1.81 & 1.77 & 1.49 & 1.91 & 1.67 & 1.76 \\
\hline & $(1.81)$ & $(1.90)$ & $(1.82)$ & $(1.49)$ & $(2.01)$ & $(1.67)$ & $(1.77)$ \\
\hline \multirow[t]{2}{*}{ Exposure*auction } & $-2.82^{*}$ & $-2.62^{* *}$ & $-3.15^{* *}$ & $-0.68^{* *}$ & -0.01 & $-0.63^{* *}$ & $-0.65^{* *}$ \\
\hline & $(-2.08)$ & $(-5.22)$ & $(-2.92)$ & $(-3.86)$ & $(-1.54)$ & $(-3.17)$ & $(-3.27)$ \\
\hline \multirow[t]{2}{*}{ Exposure*dir } & -4.70 & -17.02 & -16.26 & -1.73 & 0.01 & $-1.46^{* *}$ & $-1.41^{* *}$ \\
\hline & $(-0.24)$ & $(-1.84)$ & $(-0.97)$ & $(-1.34)$ & $(0.10)$ & $(-2.74)$ & $(-2.84)$ \\
\hline \multirow[t]{2}{*}{ Transp*auction } & -0.39 & -0.42 & -0.35 & -0.34 & -0.32 & $-0.58^{*}$ & $-0.58^{*}$ \\
\hline & $(-1.23)$ & $(-1.50)$ & $(-1.17)$ & $(-1.03)$ & $(-0.97)$ & $(-2.07)$ & $(-2.08)$ \\
\hline \multirow[t]{2}{*}{ Transp*dir } & -0.33 & 0.08 & 0.19 & -1.00 & -0.74 & -0.70 & -0.72 \\
\hline & $(-0.21)$ & $(0.09)$ & $(0.14)$ & $(-1.24)$ & $(-0.65)$ & $(-1.00)$ & $(-1.03)$ \\
\hline \multirow[t]{2}{*}{ Illiquid $*$ auction } & 1.26 & 0.33 & 0.44 & 0.56 & 0.33 & 0.48 & 0.53 \\
\hline & $(0.79)$ & $(0.50)$ & $(0.59)$ & $(0.93)$ & $(0.40)$ & $(0.73)$ & $(0.80)$ \\
\hline \multirow[t]{2}{*}{ Illiquid $*$ dir } & -254.49 & -103.10 & -132.89 & -150.13 & -282.19 & $-198.59^{* *}$ & $-200.98^{* *}$ \\
\hline & $(-1.72)$ & $(-1.09)$ & $(-0.95)$ & $(-1.61)$ & $(-1.59)$ & $(-2.71)$ & $(-2.75)$ \\
\hline \multirow[t]{2}{*}{ Exposure*SP500 } & $-6.97^{* *}$ & $-6.03^{* *}$ & $-8.16^{* *}$ & $-1.85^{* *}$ & $-0.03^{* *}$ & $-1.99^{* *}$ & $-1.98^{* *}$ \\
\hline & $(-5.20)$ & $(-4.57)$ & $(-6.19)$ & $(-21.01)$ & $(-4.86)$ & $(-15.35)$ & $(-14.60)$ \\
\hline \multirow[t]{2}{*}{$\Delta$ Default } & 0.35 & 0.48 & 0.28 & 0.61 & $1.50^{*}$ & 0.66 & 0.67 \\
\hline & $(0.51)$ & $(0.76)$ & $(0.43)$ & $(0.85)$ & $(2.08)$ & $(0.90)$ & $(0.92)$ \\
\hline Num of Obs & 4005 & 4005 & 4005 & 4005 & 3607 & 4005 & 4005 \\
\hline$R^{2}$ & 0.201 & 0.201 & 0.213 & 0.241 & 0.210 & 0.218 & 0.217 \\
\hline
\end{tabular}

t statistic in parentheses; OLS with country fixed effects, monthly time dummies, and robust standard errors.

${ }^{*} p<0.05,{ }^{* *} p<0.01$ 
Table 9: Slope coefficients for recipients in announcements

\begin{tabular}{lccccccc}
\hline \hline & $(1)$ & $(2)$ & $(3)$ & $(4)$ & $(5)$ & $(6)$ & $(7)$ \\
& Exports & Imports & Trade & Assets(TIC) & Assets(CPIS) & Debt & LTdebt \\
\hline Exposure*major & -0.23 & $-3.93^{* *}$ & -1.02 & $-0.61^{* *}$ & -0.01 & $-0.50^{* *}$ & $-0.49^{* *}$ \\
& $(-0.43)$ & $(-4.91)$ & $(-0.97)$ & $(-3.27)$ & $(-1.99)$ & $(-5.73)$ & $(-5.55)$ \\
Transp*major & -0.09 & $-0.23^{* *}$ & -0.06 & $-0.39^{*}$ & -0.05 & $-0.47^{* *}$ & $-0.47^{* *}$ \\
& $(-0.68)$ & $(-2.99)$ & $(-0.49)$ & $(-2.27)$ & $(-0.40)$ & $(-3.28)$ & $(-3.17)$ \\
Illiquid $*$ major & $-21.87^{* *}$ & -2.93 & $-17.83^{*}$ & 2.74 & 0.44 & $-21.73^{* *}$ & $-22.10^{* *}$ \\
& $(-3.57)$ & $(-0.29)$ & $(-2.57)$ & $(0.27)$ & $(0.03)$ & $(-5.48)$ & $(-5.57)$ \\
Exposure*other & $-6.89^{*}$ & -0.42 & -1.67 & $-1.16^{* *}$ & 0.02 & $2.39^{* *}$ & 0.05 \\
& $(-2.20)$ & $(-0.79)$ & $(-1.87)$ & $(-6.95)$ & $(1.21)$ & $(3.88)$ & $(0.03)$ \\
Transp*other & $2.01^{* *}$ & $2.00^{* *}$ & $2.69^{* *}$ & $1.29^{* *}$ & $3.00^{* *}$ & $5.44^{* *}$ & 2.91 \\
& $(2.93)$ & $(15.65)$ & $(20.61)$ & $(3.86)$ & $(7.63)$ & $(6.53)$ & $(1.61)$ \\
Illiquid $*$ other & -34.07 & $146.83^{*}$ & $134.03^{*}$ & $49.01^{*}$ & -25.10 & $-135.02^{* *}$ & 58.81 \\
& $(-0.93)$ & $(2.08)$ & $(2.56)$ & $(2.57)$ & $(-0.35)$ & $(-3.42)$ & $(0.51)$ \\
\hline Num of Obs & 4000 & 4000 & 4000 & 4000 & 3601 & 4000 & 4000 \\
$R^{2}$ & 0.232 & 0.230 & 0.242 & 0.269 & 0.240 & 0.246 & 0.244 \\
\hline \hline
\end{tabular}

Coefficients in table are presented in hundreds

$\mathrm{t}$ statistic in parentheses; OLS with country fixed effects, monthly time dummies, and robust standard errors.

Major central banks include:

European Central Bank, Swiss National Bank, Bank of Japan, Bank of England, and Bank of Canada.

${ }^{*} p<0.05,{ }^{* *} p<0.01$ 
Table A1: Add Level Effects to Interaction Terms

\begin{tabular}{|c|c|c|c|c|c|c|c|}
\hline & $(1)$ & $(2)$ & $(3)$ & (4) & $(5)$ & $(6)$ & (7) \\
\hline & Exports & Imports & Trade & Assets(TIC) & Assets(CPIS) & Debt & LTdebt \\
\hline \multirow[t]{2}{*}{ ExposureXauction } & $-2.52^{*}$ & $-2.49^{* *}$ & $-3.00^{* *}$ & $-0.63^{* *}$ & -0.01 & $-0.68^{* *}$ & $-0.69^{* *}$ \\
\hline & $(-2.01)$ & $(-4.90)$ & $(-2.95)$ & $(-3.98)$ & $(-1.35)$ & $(-3.70)$ & $(-3.86)$ \\
\hline \multirow[t]{2}{*}{ TranspXauction } & $-0.61^{*}$ & $-0.61^{*}$ & $-0.55^{*}$ & $-0.59^{*}$ & $-0.56^{*}$ & $-0.74^{* *}$ & $-0.74^{* *}$ \\
\hline & $(-2.25)$ & $(-2.64)$ & $(-2.19)$ & $(-2.52)$ & $(-2.27)$ & $(-3.20)$ & $(-3.25)$ \\
\hline \multirow[t]{2}{*}{ IlliquidXauction } & 0.63 & -0.13 & 0.13 & 0.31 & -0.27 & 0.35 & 0.41 \\
\hline & $(0.37)$ & $(-0.19)$ & $(0.16)$ & $(0.51)$ & $(-0.28)$ & $(0.48)$ & $(0.55)$ \\
\hline \multirow[t]{2}{*}{ Exposure } & -4.52 & -6.91 & -7.60 & 10.44 & 0.05 & $2.55^{*}$ & $2.24^{*}$ \\
\hline & $(-1.46)$ & $(-0.87)$ & $(-1.01)$ & $(1.98)$ & $(0.98)$ & $(2.50)$ & $(2.13)$ \\
\hline \multirow[t]{2}{*}{ Transp } & 1.78 & 2.49 & 1.82 & 2.60 & 4.90 & 5.01 & 3.94 \\
\hline & $(0.66)$ & $(0.88)$ & $(0.67)$ & $(0.79)$ & $(1.78)$ & $(1.33)$ & $(1.23)$ \\
\hline \multirow[t]{2}{*}{ Illiquid } & $14.24^{*}$ & $15.24^{*}$ & $12.63^{*}$ & 13.65 & $15.14^{*}$ & 11.42 & 11.17 \\
\hline & $(2.10)$ & $(2.61)$ & $(2.26)$ & $(1.53)$ & $(2.04)$ & $(1.75)$ & (1.61) \\
\hline \multirow[t]{2}{*}{ ExposureXSP500 } & $-6.99^{* *}$ & $-6.05^{* *}$ & $-8.17^{* *}$ & $-1.85^{* *}$ & $-0.03^{* *}$ & $-2.00^{* *}$ & $-1.98^{* *}$ \\
\hline & $(-5.21)$ & $(-4.58)$ & $(-6.19)$ & $(-20.91)$ & $(-4.88)$ & $(-15.31)$ & $(-14.59)$ \\
\hline \multirow[t]{2}{*}{ Chg_Default } & 0.37 & 0.48 & 0.29 & 0.61 & $1.52^{*}$ & 0.66 & 0.67 \\
\hline & $(0.53)$ & $(0.76)$ & $(0.44)$ & $(0.85)$ & $(2.12)$ & $(0.91)$ & $(0.92)$ \\
\hline$N$ & 4000 & 4000 & 4000 & 4000 & 3601 & 4000 & 4000 \\
\hline$R^{2}$ & 0.201 & 0.200 & 0.212 & 0.241 & 0.209 & 0.217 & 0.216 \\
\hline
\end{tabular}

$t$ statistics in parentheses

$\mathrm{t}$ statistic in parentheses; OLS with country fixed effects, monthly time dummies, and robust standard errors.

${ }^{*} p<0.05,{ }^{* *} p<0.01$ 
Table A2: Base specification without time dummies

\begin{tabular}{lccccccc}
\hline \hline & $(1)$ & $(2)$ & $(3)$ & $(4)$ & $(5)$ & $(6)$ & $(7)$ \\
& Exports & Imports & Trade & Assets(TIC) & Assets(CPIS) & Debt & LTdebt \\
\hline auction & 0.38 & $0.49^{*}$ & 0.43 & 0.25 & 0.32 & -0.04 & 0.05 \\
& $(1.69)$ & $(2.26)$ & $(1.72)$ & $(0.91)$ & $(1.21)$ & $(-0.10)$ & $(0.14)$ \\
Exposure*auction & -1.54 & $-2.49^{* *}$ & -2.34 & -0.29 & -0.00 & -0.01 & -0.10 \\
& $(-1.30)$ & $(-3.89)$ & $(-1.68)$ & $(-1.52)$ & $(-0.88)$ & $(-0.02)$ & $(-0.27)$ \\
Transp*auction & -0.26 & -0.33 & -0.30 & -0.14 & -0.27 & 0.26 & 0.15 \\
& $(-0.63)$ & $(-0.83)$ & $(-0.72)$ & $(-0.32)$ & $(-0.57)$ & $(0.43)$ & $(0.27)$ \\
Illiquid*auction & -1.53 & -0.29 & -0.49 & -0.80 & -0.76 & -1.52 & -1.32 \\
& $(-1.03)$ & $(-0.39)$ & $(-0.62)$ & $(-0.79)$ & $(-0.80)$ & $(-0.91)$ & $(-0.85)$ \\
Exposure*SP500 & $-8.82^{* *}$ & $-7.59^{* *}$ & $-10.05^{* *}$ & $-2.17^{* *}$ & $-0.04^{* *}$ & $-2.44^{* *}$ & $-2.43^{* *}$ \\
& $(-5.75)$ & $(-4.62)$ & $(-6.72)$ & $(-22.59)$ & $(-5.54)$ & $(-16.93)$ & $(-16.09)$ \\
$\Delta$ Default & 0.65 & 0.79 & 0.54 & 0.90 & $2.19^{*}$ & 1.01 & 1.02 \\
& $(0.68)$ & $(0.88)$ & $(0.60)$ & $(0.94)$ & $(2.43)$ & $(1.01)$ & $(1.02)$ \\
\hline Num of Obs & 4005 & 4005 & 4005 & 4005 & 3607 & 4005 & 4005 \\
$R^{2}$ & 0.108 & 0.106 & 0.126 & 0.164 & 0.122 & 0.130 & 0.129 \\
\hline \hline
\end{tabular}

$\mathrm{t}$ statistic in parentheses; OLS with country fixed effects and robust standard errors.

${ }^{*} p<0.05,{ }^{* *} p<0.01$ 
Table A3: Base specification with weekly time dummies

\begin{tabular}{lccccccc}
\hline \hline & $(1)$ & $(2)$ & $(3)$ & $(4)$ & $(5)$ & $(6)$ & $(7)$ \\
& Exports & Imports & Trade & Assets(TIC) & Assets(CPIS) & Debt & LTdebt \\
\hline Exposure*auction & -0.34 & -0.84 & -0.79 & -0.05 & 0.00 & 0.26 & 0.15 \\
& $(-0.28)$ & $(-1.67)$ & $(-0.65)$ & $(-0.25)$ & $(0.30)$ & $(0.77)$ & $(0.48)$ \\
Transp*auction & -0.13 & -0.16 & -0.16 & -0.09 & -0.11 & 0.27 & 0.15 \\
& $(-0.36)$ & $(-0.46)$ & $(-0.45)$ & $(-0.22)$ & $(-0.27)$ & $(0.49)$ & $(0.30)$ \\
Illiquid*auction & 0.77 & 0.30 & 0.41 & 0.22 & 0.27 & -0.33 & -0.14 \\
& $(0.52)$ & $(0.44)$ & $(0.53)$ & $(0.30)$ & $(0.32)$ & $(-0.26)$ & $(-0.13)$ \\
Exposure*SP500 & 0.22 & -0.47 & -0.08 & $-0.44^{* *}$ & 0.00 & $-0.37^{*}$ & $-0.41^{*}$ \\
& $(0.24)$ & $(-0.74)$ & $(-0.07)$ & $(-3.05)$ & $(0.54)$ & $(-2.22)$ & $(-2.56)$ \\
Chg_Default & -0.08 & -0.11 & -0.09 & -0.09 & 0.49 & -0.08 & -0.08 \\
& $(-0.19)$ & $(-0.25)$ & $(-0.23)$ & $(-0.20)$ & $(1.00)$ & $(-0.19)$ & $(-0.19)$ \\
\hline Num of Obs & 4005 & 4005 & 4005 & 4005 & 3607 & 4005 & 4005 \\
$R^{2}$ & 0.522 & 0.522 & 0.522 & 0.524 & 0.534 & 0.523 & 0.524 \\
\hline \hline
\end{tabular}

$t$ statistics in parentheses

t statistic in parentheses; OLS with country fixed effects, weekly time dummies, and robust standard errors.

${ }^{*} p<0.05,{ }^{* *} p<0.01$ 
Table A4: Exposure as share of GDP

\begin{tabular}{lccccccc}
\hline \hline & $(1)$ & $(2)$ & $(3)$ & $(4)$ & $(5)$ & $(6)$ & $(7)$ \\
& Exports & Imports & Trade & Assets(TIC) & Assets(CPIS) & Debt & LTdebt \\
\hline ExposureXauction & -3.79 & $-10.76^{* *}$ & $-4.13^{*}$ & $-0.87^{*}$ & -0.26 & -0.44 & -0.75 \\
& $(-2.00)$ & $(-5.45)$ & $(-2.39)$ & $(-2.48)$ & $(-1.42)$ & $(-1.44)$ & $(-1.47)$ \\
TranspXauction & $-0.68^{* *}$ & -0.44 & $-0.50^{*}$ & $-0.77^{* *}$ & $-0.72^{* *}$ & $-0.73^{* *}$ & $-0.70^{* *}$ \\
& $(-2.82)$ & $(-1.88)$ & $(-2.03)$ & $(-3.38)$ & $(-3.22)$ & $(-3.22)$ & $(-3.07)$ \\
IlliquidXauction & 0.19 & $3.35^{*}$ & 1.15 & 2.06 & 0.28 & 0.53 & 0.64 \\
& $(0.39)$ & $(2.22)$ & $(1.26)$ & $(1.77)$ & $(0.41)$ & $(0.79)$ & $(0.89)$ \\
ExposureXSP500 & $-17.25^{* *}$ & $-19.61^{* *}$ & $-12.19^{* *}$ & $-2.00^{* *}$ & $-1.43^{*}$ & $-1.75^{*}$ & $-2.89^{*}$ \\
& $(-3.61)$ & $(-4.17)$ & $(-5.50)$ & $(-3.18)$ & $(-2.39)$ & $(-2.40)$ & $(-2.35)$ \\
Chg_Default & 0.52 & 0.70 & 0.52 & 0.86 & $1.83^{* *}$ & $1.84^{* *}$ & $1.84^{* *}$ \\
& $(0.72)$ & $(1.02)$ & $(0.72)$ & $(1.28)$ & $(3.04)$ & $(3.04)$ & $(3.04)$ \\
\hline$N$ & 3953 & 3953 & 3953 & 3953 & 3555 & 3542 & 3465 \\
$R^{2}$ & 0.185 & 0.202 & 0.210 & 0.173 & 0.162 & 0.160 & 0.163 \\
\hline \hline
\end{tabular}

$t$ statistics in parentheses

t statistic in parentheses; OLS with country fixed effects, monthly time dummies, and robust standard errors.

${ }^{*} p<0.05,{ }^{* *} p<0.01$ 
Table A4: BIS Bank Exposure Measure

\begin{tabular}{|c|c|c|}
\hline & (1) & $(2)$ \\
\hline & US Bank Exp & BIS_GDP \\
\hline \multirow[t]{2}{*}{ ExposureXauction } & $-2.76^{* *}$ & -0.28 \\
\hline & $(-3.30)$ & $(-0.50)$ \\
\hline \multirow[t]{2}{*}{ TranspXauction } & 0.32 & -0.28 \\
\hline & $(0.79)$ & $(-0.75)$ \\
\hline \multirow[t]{2}{*}{ IlliquidXauction } & $1.75^{*}$ & -1.16 \\
\hline & $(2.39)$ & $(-0.70)$ \\
\hline \multirow[t]{2}{*}{ ExposureXSP500 } & $-3.81^{* *}$ & $-1.96^{*}$ \\
\hline & $(-3.99)$ & $(-2.47)$ \\
\hline \multirow[t]{2}{*}{ Chg_Default } & 2.18 & 2.34 \\
\hline & $(1.51)$ & $(1.53)$ \\
\hline$N$ & 1622 & 1622 \\
\hline$R^{2}$ & 0.195 & 0.175 \\
\hline
\end{tabular}


Table A6: Euro area aggregated into one country

\begin{tabular}{lccccccc}
\hline \hline & $(1)$ & $(2)$ & $(3)$ & $(4)$ & $(5)$ & $(6)$ & $(7)$ \\
& Exports & Imports & Trade & Assets(TIC) & Assets(CPIS) & Debt & LTdebt \\
\hline ExposureXauction & $-2.91^{*}$ & $-2.62^{* *}$ & $-3.25^{* *}$ & $-0.69^{* *}$ & -0.01 & $-0.69^{* *}$ & $-0.71^{* *}$ \\
& $(-2.17)$ & $(-5.03)$ & $(-2.99)$ & $(-3.81)$ & $(-1.39)$ & $(-3.38)$ & $(-3.49)$ \\
TranspXauction & $-0.70^{*}$ & $-0.71^{*}$ & $-0.64^{*}$ & $-0.64^{*}$ & $-0.64^{*}$ & $-0.87^{* *}$ & $-0.87^{* *}$ \\
& $(-2.12)$ & $(-2.58)$ & $(-2.09)$ & $(-2.10)$ & $(-2.06)$ & $(-3.14)$ & $(-3.16)$ \\
IlliquidXauction & 1.68 & 0.59 & 0.74 & 0.91 & 0.60 & 0.86 & 0.91 \\
& $(1.07)$ & $(1.01)$ & $(1.14)$ & $(1.55)$ & $(0.75)$ & $(1.24)$ & $(1.29)$ \\
ExposureXSP500 & $-6.75^{* *}$ & $-5.92^{* *}$ & $-7.97^{* *}$ & $-1.90^{* *}$ & $-0.03^{* *}$ & $-2.09^{* *}$ & $-2.07^{* *}$ \\
& $(-5.15)$ & $(-4.65)$ & $(-6.21)$ & $(-21.48)$ & $(-4.82)$ & $(-16.40)$ & $(-15.54)$ \\
Chg_Default & 0.24 & 0.36 & 0.15 & 0.46 & & & \\
& $(0.34)$ & $(0.56)$ & $(0.23)$ & $(0.64)$ & $(1.86)$ & $(0.69)$ & $(0.71)$ \\
\hline$N$ & 3258 & 3258 & 3258 & 3258 & 2860 & 3258 & 3258 \\
$R^{2}$ & 0.217 & 0.218 & 0.232 & 0.277 & 0.231 & 0.247 & 0.246 \\
\hline \hline
\end{tabular}

$t$ statistics in parentheses

t statistic in parentheses; OLS with country fixed effects, monthly time dummies, and robust standard errors.

${ }^{*} p<0.05,{ }^{* *} p<0.01$ 
Table A7: Single Word Google Search Results, Foreign Long-Term Debt

\begin{tabular}{|c|c|c|c|c|c|}
\hline Word & Coeff & T-stat & R-sq & \# of countries & \# of obs \\
\hline arrears & 0.00263 & 0.63969 & 0.00007 & 4 & 89 \\
\hline balance & -0.00804 & -0.78951 & 0.00037 & 73 & 3103 \\
\hline bankruptcy & 0.00482 & 0.34133 & 0.00010 & 48 & 1081 \\
\hline bond & -0.03614 & -1.37083 & 0.00767 & 83 & 3342 \\
\hline collapse & -0.00289 & -1.01006 & 0.00030 & 56 & 1140 \\
\hline contraction & - & - & - & 5 & 77 \\
\hline credit & -0.04056 & -1.14338 & 0.00494 & 100 & 4705 \\
\hline crisis & $-0.01548^{* *}$ & -30.78583 & 0.07466 & 96 & 3779 \\
\hline currency & -0.01646 & -1.11072 & 0.00107 & 105 & 6703 \\
\hline danger & -0.00613 & -1.33332 & 0.00079 & 52 & 1352 \\
\hline debt & -0.01316 & -1.15926 & 0.00142 & 82 & 2866 \\
\hline deficit & 0.01410 & 1.15733 & 0.00159 & 56 & 1443 \\
\hline depression & 0.00430 & 0.38199 & 0.00012 & 55 & 1814 \\
\hline disaster & -0.00028 & -0.35360 & 0.00000 & 68 & 2321 \\
\hline downturn & 0.00212 & 0.88936 & 0.00002 & 10 & 159 \\
\hline equity & -0.00429 & -1.03095 & 0.00015 & 67 & 2694 \\
\hline exposure & -0.01607 & -0.71277 & 0.00163 & 34 & 769 \\
\hline failure & -0.01601 & -0.53411 & 0.00175 & 62 & 2014 \\
\hline financial & $-0.06121^{*}$ & -2.26033 & 0.03905 & 100 & 4910 \\
\hline freeze & $-0.02815^{* *}$ & -3.51057 & 0.00332 & 43 & 807 \\
\hline insolvency & 0.00227 & 0.89918 & 0.00004 & 15 & 356 \\
\hline liability & -0.00110 & -0.07959 & 0.00000 & 41 & 1136 \\
\hline liquidity & 0.01442 & 1.23534 & 0.00092 & 16 & 332 \\
\hline market & -0.03413 & -1.07742 & 0.00426 & 104 & 5908 \\
\hline overdue & - & - & - & 2 & 33 \\
\hline recession & 0.00103 & 0.28506 & 0.00002 & 55 & 910 \\
\hline risk & -0.01965 & -1.01747 & 0.00172 & 86 & 3503 \\
\hline safety & -0.01318 & -1.24273 & 0.00058 & 93 & 4365 \\
\hline shortage & -0.00072 & -0.27161 & 0.00002 & 42 & 1005 \\
\hline stock & -0.04151 & -1.52674 & 0.02512 & 97 & 5093 \\
\hline $\operatorname{tax}$ & -0.01440 & -1.00984 & 0.00067 & 101 & 5635 \\
\hline unpaid & -0.01309 & -1.27611 & 0.00037 & 13 & 230 \\
\hline
\end{tabular}

OLS estimation with robust standard errors. 
Table A8: Google default proxy generated from ad hoc word list

\begin{tabular}{lccccccc}
\hline \hline & $(1)$ & $(2)$ & $(3)$ & $(4)$ & $(5)$ & $(6)$ & $(7)$ \\
& Exports & Imports & Trade & Assets(TIC) & Assets(CPIS) & Debt & LTdebt \\
\hline ExposureXauction & $-2.84^{*}$ & $-2.62^{* *}$ & $-3.20^{* *}$ & $-0.66^{* *}$ & -0.01 & $-0.70^{* *}$ & $-0.72^{* *}$ \\
& $(-2.13)$ & $(-4.82)$ & $(-3.00)$ & $(-4.29)$ & $(-1.50)$ & $(-3.93)$ & $(-4.03)$ \\
TranspXauction & $-0.55^{*}$ & $-0.57^{*}$ & $-0.51^{*}$ & $-0.54^{*}$ & $-0.50^{*}$ & $-0.72^{* *}$ & $-0.72^{* *}$ \\
& $(-2.02)$ & $(-2.51)$ & $(-2.02)$ & $(-2.29)$ & $(-2.02)$ & $(-3.18)$ & $(-3.19)$ \\
IlliquidXauction & 1.57 & 0.66 & 0.80 & 1.00 & 0.51 & 1.00 & 1.05 \\
& $(0.99)$ & $(1.22)$ & $(1.19)$ & $(1.94)$ & $(0.65)$ & $(1.70)$ & $(1.77)$ \\
ExposureXSP500 & $-6.97^{* *}$ & $-6.04^{* *}$ & $-8.13^{* *}$ & $-1.79^{* *}$ & $-0.03^{* *}$ & $-1.94^{* *}$ & $-1.92^{* *}$ \\
& $(-5.22)$ & $(-4.63)$ & $(-6.26)$ & $(-17.85)$ & $(-5.03)$ & $(-14.40)$ & $(-13.63)$ \\
& & & & & & & \\
chg_google_old & 0.01 & 0.01 & 0.01 & 0.01 & $0.02^{* *}$ & 0.01 & 0.01 \\
& $(1.05)$ & $(1.38)$ & $(1.00)$ & $(1.29)$ & $(3.17)$ & $(1.36)$ & $(1.37)$ \\
\hline$N$ & 4223 & 4223 & 4223 & 4223 & 3813 & 4223 & 4223 \\
$R^{2}$ & 0.202 & 0.201 & 0.213 & 0.239 & 0.210 & 0.217 & 0.216 \\
\hline \hline
\end{tabular}

$t$ statistics in parentheses

t statistic in parentheses; OLS with country fixed effects, monthly time dummies, and robust standard errors.

${ }^{*} p<0.05,{ }^{* *} p<0.01$ 
Table A9: Changes in Exchange Rates added as independent variable

\begin{tabular}{lccccccc}
\hline \hline & $(1)$ & $(2)$ & $(3)$ & $(4)$ & $(5)$ & $(6)$ & $(7)$ \\
& Exports & Imports & Trade & Assets(TIC) & Assets(CPIS) & Debt & LTdebt \\
\hline pct_fx & 0.27 & 0.14 & 0.17 & -0.10 & 0.18 & 0.07 & 0.05 \\
& $(0.83)$ & $(0.45)$ & $(0.54)$ & $(-0.32)$ & $(0.58)$ & $(0.24)$ & $(0.18)$ \\
ExposureXauction & -2.71 & $-2.50^{* *}$ & $-3.03^{*}$ & $-0.64^{* *}$ & -0.01 & $-0.65^{* *}$ & $-0.68^{* *}$ \\
& $(-1.95)$ & $(-4.83)$ & $(-2.67)$ & $(-3.95)$ & $(-1.31)$ & $(-3.48)$ & $(-3.61)$ \\
TranspXauction & $-0.61^{*}$ & $-0.63^{* *}$ & $-0.57^{*}$ & $-0.58^{*}$ & $-0.57^{*}$ & $-0.75^{* *}$ & $-0.75^{* *}$ \\
& $(-2.14)$ & $(-2.71)$ & $(-2.15)$ & $(-2.37)$ & $(-2.25)$ & $(-3.23)$ & $(-3.24)$ \\
IlliquidXauction & 1.48 & 0.68 & 0.80 & 0.90 & 0.48 & 0.88 & 0.93 \\
& $(0.91)$ & $(1.23)$ & $(1.19)$ & $(1.68)$ & $(0.61)$ & $(1.42)$ & $(1.50)$ \\
ExposureXSP500 & $-6.95^{* *}$ & $-5.99^{* *}$ & $-8.11^{* *}$ & $-1.87^{* *}$ & $-0.03^{* *}$ & $-2.00^{* *}$ & $-1.99^{* *}$ \\
& $(-5.22)$ & $(-4.49)$ & $(-6.15)$ & $(-18.51)$ & $(-4.84)$ & $(-14.38)$ & $(-13.57)$ \\
& & & & & & & \\
Chg_Default & 0.36 & 0.49 & 0.29 & 0.60 & $1.52^{*}$ & 0.66 & 0.67 \\
& $(0.52)$ & $(0.76)$ & $(0.43)$ & $(0.84)$ & $(2.08)$ & $(0.90)$ & $(0.92)$ \\
\hline$N$ & 3991 & 3991 & 3991 & 3991 & 3600 & 3991 & 3991 \\
$R^{2}$ & 0.202 & 0.200 & 0.213 & 0.241 & 0.209 & 0.217 & 0.217 \\
\hline \hline
\end{tabular}

$t$ statistics in parentheses

t statistic in parentheses; OLS with country fixed effects, monthly time dummies, and robust standard errors.

${ }^{*} p<0.05,{ }^{* *} p<0.01$ 
Table A10: Changes in Exchange Rates as dependent variable

\begin{tabular}{lccccccc}
\hline \hline & $(1)$ & $(2)$ & $(3)$ & $(4)$ & $(5)$ & $(6)$ & $(7)$ \\
& Exports & Imports & Trade & Assets(TIC) & Assets(CPIS) & Debt & LTdebt \\
\hline ExposureXauction & -0.13 & -0.05 & -0.10 & -0.03 & -0.00 & -0.03 & -0.04 \\
& $(-1.62)$ & $(-0.65)$ & $(-0.85)$ & $(-1.11)$ & $(-1.64)$ & $(-1.28)$ & $(-1.49)$ \\
TranspXauction & 0.02 & 0.01 & 0.02 & 0.02 & 0.05 & 0.02 & 0.02 \\
& $(0.59)$ & $(0.37)$ & $(0.52)$ & $(0.61)$ & $(1.18)$ & $(0.49)$ & $(0.54)$ \\
IlliquidXauction & $-0.00^{*}$ & $-0.00^{* *}$ & -0.00 & $-0.00^{*}$ & -0.00 & $-0.00^{* *}$ & $-0.00^{*}$ \\
& $(-2.02)$ & $(-2.71)$ & $(-1.98)$ & $(-2.65)$ & $(-0.15)$ & $(-2.66)$ & $(-2.38)$ \\
ExposureXSP500 & -0.11 & $-0.29^{* *}$ & $-0.28^{*}$ & $-0.11^{* *}$ & -0.00 & $-0.09^{* *}$ & $-0.09^{*}$ \\
& $(-1.25)$ & $(-2.86)$ & $(-2.03)$ & $(-3.87)$ & $(-1.25)$ & $(-2.75)$ & $(-2.15)$ \\
& & & & & & & \\
Chg_Default & -0.01 & -0.02 & -0.02 & -0.02 & -0.05 & -0.01 & -0.01 \\
& $(-0.17)$ & $(-0.32)$ & $(-0.37)$ & $(-0.42)$ & $(-0.64)$ & $(-0.28)$ & $(-0.25)$ \\
\hline$N$ & 5778 & 5778 & 5778 & 5778 & 4897 & 5778 & 5778 \\
$R^{2}$ & 0.012 & 0.022 & 0.017 & 0.035 & 0.015 & 0.022 & 0.021 \\
\hline \hline
\end{tabular}

$t$ statistics in parentheses

t statistic in parentheses; OLS with country fixed effects, monthly time dummies, and robust standard errors.

${ }^{*} p<0.05,{ }^{* *} p<0.01$ 
Table A11: LIBOR-OIS Spreads as dependent variable

\begin{tabular}{lccccccc}
\hline \hline & $(1)$ & $(2)$ & $(3)$ & $(4)$ & $(5)$ & $(6)$ & $(7)$ \\
& Exports & Imports & Trade & Assets(TIC) & Assets(CPIS) & Debt & LTdebt \\
\hline ExposureXauction & -0.61 & -0.03 & -0.14 & $-0.10^{*}$ & -0.00 & $-0.06^{*}$ & -0.07 \\
& $(-1.49)$ & $(-0.67)$ & $(-1.00)$ & $(-2.51)$ & $(-1.50)$ & $(-2.33)$ & $(-1.73)$ \\
TranspXauction & 0.03 & -0.01 & 0.00 & 0.01 & 0.02 & -0.01 & 0.00 \\
& $(1.12)$ & $(-0.34)$ & $(0.11)$ & $(0.42)$ & $(0.40)$ & $(-0.20)$ & $(0.03)$ \\
IlliquidXauction & 6.55 & 3.90 & 4.32 & $6.59^{*}$ & 4.43 & 4.95 & 5.15 \\
& $(1.59)$ & $(1.32)$ & $(1.44)$ & $(2.25)$ & $(2.00)$ & $(1.77)$ & $(1.84)$ \\
ExposureXSP500 & -0.04 & $-0.01^{*}$ & -0.02 & $-0.03^{*}$ & $-0.00^{*}$ & $-0.04^{*}$ & $-0.03^{*}$ \\
& $(-0.96)$ & $(-2.36)$ & $(-1.82)$ & $(-2.56)$ & $(-2.27)$ & $(-2.47)$ & $(-2.31)$ \\
Chg_Default & 0.12 & 0.12 & 0.12 & 0.12 & 0.12 & 0.12 & 0.12 \\
& $(1.73)$ & $(1.70)$ & $(1.71)$ & $(1.68)$ & $(1.68)$ & $(1.67)$ & $(1.68)$ \\
\hline$N$ & 1154 & 1154 & 1154 & 1154 & 1154 & 1154 & 1154 \\
$R^{2}$ & 0.072 & 0.067 & 0.067 & 0.077 & 0.068 & 0.074 & 0.075 \\
\hline \hline
\end{tabular}

$t$ statistics in parentheses

t statistic in parentheses; OLS with country fixed effects, monthly time dummies, and robust standard errors.

${ }^{*} p<0.05,{ }^{* *} p<0.01$ 
Table A12: Illiquidity proxied by ST Debt/GDP

\begin{tabular}{lccccccc}
\hline \hline & $(1)$ & $(2)$ & $(3)$ & $(4)$ & $(5)$ & $(6)$ & $(7)$ \\
& Exports & Imports & Trade & Assets(TIC) & Assets(CPIS) & Debt & LTdebt \\
\hline Exposure*auction & $-2.66^{*}$ & $-2.57^{* *}$ & $-3.19^{* *}$ & $-0.63^{* *}$ & -0.01 & $-0.64^{* *}$ & $-0.66^{* *}$ \\
& $(-2.42)$ & $(-4.90)$ & $(-2.88)$ & $(-3.96)$ & $(-1.45)$ & $(-3.55)$ & $(-3.66)$ \\
Transp*auction & $-0.57^{*}$ & $-0.59^{*}$ & $-0.52^{*}$ & $-0.56^{*}$ & $-0.53^{*}$ & $-0.72^{* *}$ & $-0.72^{* *}$ \\
& $(-2.08)$ & $(-2.62)$ & $(-2.06)$ & $(-2.39)$ & $(-2.14)$ & $(-3.24)$ & $(-3.25)$ \\
ill_gdp*auction & 0.60 & 0.33 & 0.57 & 0.35 & 0.32 & 0.26 & 0.23 \\
& $(1.16)$ & $(1.20)$ & $(1.46)$ & $(1.14)$ & $(0.91)$ & $(1.00)$ & $(0.88)$ \\
Exposure*SP500 & $-6.96^{* *}$ & $-6.03^{* *}$ & $-8.14^{* *}$ & $-1.85^{* *}$ & $-0.03^{* *}$ & $-1.99^{* *}$ & $-1.98^{* *}$ \\
& $(-5.16)$ & $(-4.58)$ & $(-6.18)$ & $(-20.98)$ & $(-4.86)$ & $(-15.33)$ & $(-14.56)$ \\
Chg_Default & 0.36 & 0.49 & 0.29 & 0.61 & $1.52^{*}$ & 0.66 & 0.68 \\
& $(0.52)$ & $(0.77)$ & $(0.43)$ & $(0.86)$ & $(2.12)$ & $(0.91)$ & $(0.93)$ \\
\hline Num of Obs & 3953 & 3953 & 3953 & 3953 & 3555 & 3953 & 3953 \\
$R^{2}$ & 0.200 & 0.200 & 0.212 & 0.240 & 0.209 & 0.216 & 0.216 \\
\hline \hline
\end{tabular}

$t$ statistics in parentheses

t statistic in parentheses; OLS with country fixed effects, monthly time dummies, and robust standard errors.

${ }^{*} p<0.05,{ }^{* *} p<0.01$ 
Table A13: Illiquidity proxied by ST Debt/Reserves

\begin{tabular}{lccccccc}
\hline \hline & $(1)$ & $(2)$ & $(3)$ & $(4)$ & $(5)$ & $(6)$ & $(7)$ \\
& Exports & Imports & Trade & Assets(TIC) & Assets(CPIS) & Debt & LTdebt \\
\hline Exposure*auction & $-2.60^{*}$ & $-2.55^{* *}$ & $-3.14^{* *}$ & $-0.62^{* *}$ & -0.01 & $-0.64^{* *}$ & $-0.66^{* *}$ \\
& $(-2.51)$ & $(-4.94)$ & $(-2.92)$ & $(-3.91)$ & $(-1.46)$ & $(-3.52)$ & $(-3.63)$ \\
Transp*auction & $-0.58^{*}$ & $-0.59^{*}$ & $-0.53^{*}$ & $-0.57^{*}$ & $-0.54^{*}$ & $-0.73^{* *}$ & $-0.73^{* *}$ \\
& $(-2.12)$ & $(-2.66)$ & $(-2.09)$ & $(-2.42)$ & $(-2.18)$ & $(-3.27)$ & $(-3.28)$ \\
ill_res*auction & 0.09 & 0.02 & 0.09 & 0.00 & 0.04 & -0.00 & -0.01 \\
& $(0.85)$ & $(0.22)$ & $(0.95)$ & $(0.02)$ & $(0.44)$ & $(-0.02)$ & $(-0.12)$ \\
Exposure*SP500 & $-6.98^{* *}$ & $-6.05^{* *}$ & $-8.16^{* *}$ & $-1.85^{* *}$ & $-0.03^{* *}$ & $-2.00^{* *}$ & $-1.98^{* *}$ \\
& $(-5.19)$ & $(-4.58)$ & $(-6.20)$ & $(-21.05)$ & $(-4.87)$ & $(-15.37)$ & $(-14.61)$ \\
Chg_Default & 0.36 & 0.48 & 0.28 & 0.61 & $1.51^{*}$ & 0.66 & 0.68 \\
& $(0.52)$ & $(0.76)$ & $(0.43)$ & $(0.85)$ & $(2.11)$ & $(0.91)$ & $(0.93)$ \\
\hline Num of Obs & 4005 & 4005 & 4005 & 4005 & 3607 & 4005 & 4005 \\
$R^{2}$ & 0.200 & 0.200 & 0.212 & 0.240 & 0.209 & 0.217 & 0.216 \\
\hline \hline
\end{tabular}

$t$ statistics in parentheses

t statistic in parentheses; OLS with country fixed effects, monthly time dummies, and robust standard errors.

${ }^{*} p<0.05,{ }^{* *} p<0.01$ 
Table A14: Illiquidity proxied by Greenspan-Guidotti measure

\begin{tabular}{lccccccc}
\hline \hline & $(1)$ & $(2)$ & $(3)$ & $(4)$ & $(5)$ & $(6)$ & $(7)$ \\
& Exports & Imports & Trade & Assets(TIC) & Assets(CPIS) & Debt & LTdebt \\
\hline Exposure*auction & $-2.18^{*}$ & $-2.09^{* *}$ & $-2.49^{*}$ & $-0.44^{*}$ & -0.01 & -0.35 & -0.39 \\
& $(-2.13)$ & $(-4.04)$ & $(-2.23)$ & $(-2.16)$ & $(-1.03)$ & $(-1.19)$ & $(-1.40)$ \\
Transp*auction & -0.18 & -0.24 & -0.20 & -0.26 & -0.18 & -0.20 & -0.24 \\
& $(-0.57)$ & $(-0.74)$ & $(-0.65)$ & $(-0.72)$ & $(-0.51)$ & $(-0.43)$ & $(-0.54)$ \\
ill_GG*auction & 0.32 & 0.30 & 0.29 & 0.28 & 0.31 & 0.40 & 0.37 \\
& $(1.75)$ & $(1.51)$ & $(1.51)$ & $(1.14)$ & $(1.46)$ & $(1.27)$ & $(1.23)$ \\
Exposure*SP500 & $-6.96^{* *}$ & $-6.04^{* *}$ & $-8.16^{* *}$ & $-1.85^{* *}$ & $-0.03^{* *}$ & $-2.00^{* *}$ & $-1.98^{* *}$ \\
& $(-5.19)$ & $(-4.58)$ & $(-6.20)$ & $(-21.06)$ & $(-4.87)$ & $(-15.37)$ & $(-14.61)$ \\
Chg_Default & 0.36 & 0.48 & 0.29 & 0.61 & $1.50^{*}$ & 0.66 & 0.68 \\
& $(0.53)$ & $(0.76)$ & $(0.44)$ & $(0.85)$ & $(2.10)$ & $(0.91)$ & $(0.93)$ \\
\hline Num of Obs & 4005 & 4005 & 4005 & 4005 & 3607 & 4005 & 4005 \\
$R^{2}$ & 0.201 & 0.200 & 0.212 & 0.240 & 0.209 & 0.217 & 0.216 \\
\hline \hline
\end{tabular}

$t$ statistics in parentheses

t statistic in parentheses; OLS with country fixed effects, monthly time dummies, and robust standard errors.

${ }^{*} p<0.05,{ }^{* *} p<0.01$ 
Table A15: Non-OECD countries only

\begin{tabular}{lccccccc}
\hline \hline & $(1)$ & $(2)$ & $(3)$ & $(4)$ & $(5)$ & $(6)$ & $(7)$ \\
& Exports & Imports & Trade & Assets(TIC) & Assets(CPIS) & Debt & LTdebt \\
\hline Exposure*auction & $-3.11^{*}$ & $-2.66^{* *}$ & -2.64 & $-0.64^{*}$ & -0.00 & $-0.68^{* *}$ & $-0.72^{* *}$ \\
& $(-2.21)$ & $(-3.34)$ & $(-1.91)$ & $(-2.70)$ & $(-0.52)$ & $(-2.89)$ & $(-3.00)$ \\
Transp*auction & -0.81 & $-1.06^{* *}$ & $-0.96^{*}$ & $-0.93^{*}$ & $-1.18^{*}$ & $-1.19^{* *}$ & $-1.19^{* *}$ \\
& $(-1.86)$ & $(-3.31)$ & $(-2.47)$ & $(-2.18)$ & $(-2.66)$ & $(-3.69)$ & $(-3.69)$ \\
Illiquid*auction & 2.48 & 1.27 & 1.08 & 1.56 & 1.03 & $1.85^{*}$ & $1.93^{*}$ \\
& $(1.63)$ & $(1.74)$ & $(1.44)$ & $(1.92)$ & $(1.19)$ & $(2.40)$ & $(2.46)$ \\
Exposure*SP500 & $-6.51^{* *}$ & $-8.17^{* *}$ & $-8.15^{* *}$ & $-1.95^{* *}$ & $-0.03^{* *}$ & $-2.06^{* *}$ & $-2.10^{* *}$ \\
& $(-4.60)$ & $(-5.63)$ & $(-4.30)$ & $(-20.52)$ & $(-3.20)$ & $(-14.82)$ & $(-15.33)$ \\
\multicolumn{1}{c}{} & & & & & & \\
& $-0.63^{*}$ & $-0.56^{*}$ & $-0.71^{* *}$ & -0.44 & 0.04 & -0.30 & -0.30 \\
\hline Num of Obs & $(-2.47)$ & $(-2.63)$ & $(-3.04)$ & $(-1.77)$ & $(0.07)$ & $(-1.02)$ & $(-0.98)$ \\
$R^{2}$ & 1785 & 1785 & 1785 & 1785 & 1387 & 1785 & 1785 \\
\hline \hline
\end{tabular}

t statistic in parentheses; OLS with country fixed effects, monthly time dummies, and robust standard errors.

${ }^{*} p<0.05,{ }^{* *} p<0.01$ 
Table A16: Announcement Dates: Full Specification

\begin{tabular}{|c|c|c|c|c|c|c|c|}
\hline & $\begin{array}{c}(1) \\
\text { Exports }\end{array}$ & $\begin{array}{c}(2) \\
\text { Imports }\end{array}$ & $\begin{array}{c}(3) \\
\text { Trade }\end{array}$ & $\begin{array}{c}(4) \\
\text { Assets(TIC) }\end{array}$ & $\begin{array}{c}(5) \\
\text { Assets(CPIS) }\end{array}$ & $\begin{array}{c}(6) \\
\text { Debt }\end{array}$ & $\begin{array}{c}7) \\
\text { LTdebt }\end{array}$ \\
\hline ExposureXauction & $\begin{array}{c}-0.42 \\
(-0.43)\end{array}$ & $\begin{array}{c}-0.25 \\
(-0.68)\end{array}$ & $\begin{array}{l}-0.06 \\
(-0.07)\end{array}$ & $\begin{array}{c}0.16 \\
(1.13)\end{array}$ & $\begin{array}{c}-0.00 \\
(-0.43)\end{array}$ & $\begin{array}{c}0.14 \\
(0.78)\end{array}$ & $\begin{array}{c}0.13 \\
(0.72)\end{array}$ \\
\hline TranspXauction & $\begin{array}{c}0.20 \\
(0.70)\end{array}$ & $\begin{array}{c}0.13 \\
(0.50)\end{array}$ & $\begin{array}{c}0.05 \\
(0.17)\end{array}$ & $\begin{array}{l}-0.05 \\
(-0.23)\end{array}$ & $\begin{array}{c}0.13 \\
(0.47)\end{array}$ & $\begin{array}{c}0.19 \\
(0.76)\end{array}$ & $\begin{array}{c}0.20 \\
(0.81)\end{array}$ \\
\hline IlliquidXauction & $\begin{array}{c}-0.01 \\
(-0.58)\end{array}$ & $\begin{array}{c}0.02 \\
(1.93)\end{array}$ & $\begin{array}{c}0.01 \\
(1.05)\end{array}$ & $\begin{array}{c}0.00 \\
(0.10)\end{array}$ & $\begin{array}{c}0.01 \\
(1.09)\end{array}$ & $\begin{array}{c}-0.00 \\
(-0.59)\end{array}$ & $\begin{array}{c}-0.00 \\
(-0.50)\end{array}$ \\
\hline ExposureXdate11 & $\begin{array}{l}-14.76 \\
(-1.62)\end{array}$ & $\begin{array}{c}5.18 \\
(0.66)\end{array}$ & $\begin{array}{l}-3.48 \\
(-0.37)\end{array}$ & $\begin{array}{l}-2.69 \\
(-0.87)\end{array}$ & $\begin{array}{c}0.01 \\
(0.25)\end{array}$ & $\begin{array}{c}-0.56 \\
(-0.19)\end{array}$ & $\begin{array}{c}-0.91 \\
(-0.30)\end{array}$ \\
\hline TranspXdate11 & $\begin{array}{c}18.21^{* *} \\
(3.33)\end{array}$ & $\begin{array}{c}14.85^{* *} \\
(2.85)\end{array}$ & $\begin{array}{c}15.46^{* *} \\
(2.89)\end{array}$ & $\begin{array}{c}17.52^{* *} \\
(3.30)\end{array}$ & $\begin{array}{l}14.30^{*} \\
(2.56)\end{array}$ & $\begin{array}{c}17.83^{* *} \\
(3.47)\end{array}$ & $\begin{array}{c}18.14^{* *} \\
(3.49)\end{array}$ \\
\hline IlliquidXdate 11 & $\begin{array}{c}-0.33 \\
(-1.52)\end{array}$ & $\begin{array}{l}-0.22^{*} \\
(-2.02)\end{array}$ & $\begin{array}{l}-0.23 \\
(-1.91)\end{array}$ & $\begin{array}{l}-0.28 \\
(-1.49)\end{array}$ & $\begin{array}{c}-0.31^{* *} \\
(-3.05)\end{array}$ & $\begin{array}{l}-0.42^{*} \\
(-2.60)\end{array}$ & $\begin{array}{l}-0.40^{*} \\
(-2.39)\end{array}$ \\
\hline ExposureXdate12 & $\begin{array}{c}-3.40 \\
(-0.10)\end{array}$ & $\begin{array}{l}-25.09 \\
(-1.36)\end{array}$ & $\begin{array}{l}-18.37 \\
(-0.61)\end{array}$ & $\begin{array}{l}-8.66 \\
(-1.74)\end{array}$ & $\begin{array}{l}-0.12 \\
(-1.06)\end{array}$ & $\begin{array}{c}-7.65 \\
(-1.29)\end{array}$ & $\begin{array}{c}-8.33 \\
(-1.41)\end{array}$ \\
\hline TranspXdate 12 & $\begin{array}{c}-14.05^{*} \\
(-2.34)\end{array}$ & $\begin{array}{c}-11.44^{*} \\
(-2.12)\end{array}$ & $\begin{array}{l}-11.02 \\
(-1.92)\end{array}$ & $\begin{array}{l}-6.54 \\
(-0.99)\end{array}$ & $\begin{array}{l}-9.07 \\
(-1.40)\end{array}$ & $\begin{array}{l}-10.62 \\
(-1.78)\end{array}$ & $\begin{array}{l}-10.72 \\
(-1.81)\end{array}$ \\
\hline IlliquidXdate12 & $\begin{array}{l}-0.50 \\
(-0.91)\end{array}$ & $\begin{array}{c}-0.55 \\
(-1.76)\end{array}$ & $\begin{array}{l}-0.51 \\
(-1.62)\end{array}$ & $\begin{array}{l}-0.24 \\
(-0.59)\end{array}$ & $\begin{array}{c}-0.36 \\
(-0.94)\end{array}$ & $\begin{array}{l}-0.20 \\
(-0.43)\end{array}$ & $\begin{array}{l}-0.19 \\
(-0.39)\end{array}$ \\
\hline ExposureXdate13 & $\begin{array}{l}-42.89 \\
(-1.24)\end{array}$ & $\begin{array}{l}-39.94 \\
(-1.15)\end{array}$ & $\begin{array}{l}-42.76 \\
(-1.26)\end{array}$ & $\begin{array}{l}-7.40 \\
(-0.75)\end{array}$ & $\begin{array}{l}-0.39^{*} \\
(-2.07)\end{array}$ & $\begin{array}{c}5.79 \\
(0.58)\end{array}$ & $\begin{array}{c}4.94 \\
(0.49)\end{array}$ \\
\hline TranspXdate13 & $\begin{array}{c}97.17^{* *} \\
(4.99)\end{array}$ & $\begin{array}{c}96.36^{* *} \\
(5.02)\end{array}$ & $\begin{array}{c}97.26^{* *} \\
(4.97)\end{array}$ & $\begin{array}{c}96.73^{* *} \\
(4.83)\end{array}$ & $\begin{array}{c}108.09^{* *} \\
(5.21)\end{array}$ & $\begin{array}{c}90.89^{* *} \\
(5.09)\end{array}$ & $\begin{array}{c}91.06^{* *} \\
(5.11)\end{array}$ \\
\hline IlliquidXdate 13 & $\begin{array}{c}0.88 \\
(0.26)\end{array}$ & $\begin{array}{c}0.61 \\
(0.18)\end{array}$ & $\begin{array}{c}0.65 \\
(0.19)\end{array}$ & $\begin{array}{c}0.65 \\
(0.19)\end{array}$ & $\begin{array}{c}1.06 \\
(0.31)\end{array}$ & $\begin{array}{c}0.06 \\
(0.02)\end{array}$ & $\begin{array}{c}0.11 \\
(0.03)\end{array}$ \\
\hline ExposureXdate14 & $\begin{array}{l}-73.09 \\
(-1.62)\end{array}$ & $\begin{array}{c}-74.99^{* *} \\
(-3.54)\end{array}$ & $\begin{array}{c}-94.30^{* *} \\
(-2.85)\end{array}$ & $\begin{array}{c}-44.46^{* *} \\
(-8.11)\end{array}$ & $\begin{array}{c}-0.29 \\
(-1.10)\end{array}$ & $\begin{array}{c}-46.21^{* *} \\
(-6.79)\end{array}$ & $\begin{array}{c}-46.03^{* *} \\
(-6.69)\end{array}$ \\
\hline TranspXdate14 & $\begin{array}{c}-71.79^{* *} \\
(-6.44)\end{array}$ & $\begin{array}{c}-69.06^{* *} \\
(-6.18)\end{array}$ & $\begin{array}{c}-63.61^{* *} \\
(-5.94)\end{array}$ & $\begin{array}{c}-50.05^{* *} \\
(-7.43)\end{array}$ & $\begin{array}{c}-60.96^{* *} \\
(-4.23)\end{array}$ & $\begin{array}{c}-75.93^{* *} \\
(-8.54)\end{array}$ & $\begin{array}{c}-76.98^{* *} \\
(-8.72)\end{array}$ \\
\hline IlliquidXdate14 & $\begin{array}{c}0.68 \\
(0.52)\end{array}$ & $\begin{array}{l}-1.34^{*} \\
(-2.09)\end{array}$ & $\begin{array}{l}-0.85 \\
(-1.24)\end{array}$ & $\begin{array}{c}0.34 \\
(0.52)\end{array}$ & $\begin{array}{c}-0.75 \\
(-0.86)\end{array}$ & $\begin{array}{c}0.81 \\
(0.85)\end{array}$ & $\begin{array}{c}0.72 \\
(0.69)\end{array}$ \\
\hline ExposureXdate2 & $\begin{array}{c}-85.29^{* *} \\
(-4.50)\end{array}$ & $\begin{array}{c}-80.45^{* *} \\
(-5.04)\end{array}$ & $\begin{array}{c}-102.39^{* *} \\
(-5.56)\end{array}$ & $\begin{array}{c}-14.05^{*} \\
(-2.22)\end{array}$ & $\begin{array}{l}-0.05 \\
(-0.13)\end{array}$ & $\begin{array}{c}-17.45^{*} \\
(-2.51)\end{array}$ & $\begin{array}{c}-17.99^{*} \\
(-2.64)\end{array}$ \\
\hline TranspXdate2 & $\begin{array}{c}-25.29^{* *} \\
(-3.15)\end{array}$ & $\begin{array}{c}-24.10^{* *} \\
(-3.13)\end{array}$ & $\begin{array}{c}-21.22^{* *} \\
(-2.70)\end{array}$ & $\begin{array}{c}-31.06^{* *} \\
(-3.84)\end{array}$ & $\begin{array}{c}-30.52^{*} \\
(-2.57)\end{array}$ & $\begin{array}{c}-37.98^{* *} \\
(-4.89)\end{array}$ & $\begin{array}{c}-38.17^{* *} \\
(-4.92)\end{array}$ \\
\hline IlliquidXdate2 & $\begin{array}{c}0.65 \\
(1.76)\end{array}$ & $\begin{array}{c}-0.52 \\
(-1.65)\end{array}$ & $\begin{array}{l}-0.26 \\
(-0.60)\end{array}$ & $\begin{array}{c}-0.36 \\
(-1.30)\end{array}$ & $\begin{array}{l}-0.72 \\
(-1.08)\end{array}$ & $\begin{array}{c}-0.17 \\
(-0.47)\end{array}$ & $\begin{array}{c}-0.17 \\
(-0.46)\end{array}$ \\
\hline ExposureXSP500 & $\begin{array}{c}-4.78^{* *} \\
(-4.74)\end{array}$ & $\begin{array}{c}-4.17^{* *} \\
(-4.88)\end{array}$ & $\begin{array}{c}-5.66^{* *} \\
(-5.72)\end{array}$ & $\begin{array}{l}-1.21^{* *} \\
(-14.65)\end{array}$ & $\begin{array}{c}-0.02^{* *} \\
(-4.50)\end{array}$ & $\begin{array}{l}-1.29^{* *} \\
(-12.32)\end{array}$ & $\begin{array}{l}-1.28^{* *} \\
(-11.08)\end{array}$ \\
\hline Chg_Default & $\begin{array}{c}-0.05 \\
(-0.15) \\
\end{array}$ & $\begin{array}{c}0.03 \\
(0.08) \\
\end{array}$ & $\begin{array}{l}-0.11 \\
(-0.34) \\
\end{array}$ & $\begin{array}{c}0.11 \\
(0.28) \\
\end{array}$ & $\begin{array}{c}0.69 \\
(1.73) \\
\end{array}$ & $\begin{array}{c}0.10 \\
(0.28) \\
\end{array}$ & $\begin{array}{c}0.11 \\
(0.30)\end{array}$ \\
\hline $\begin{array}{l}N \\
R^{2}\end{array}$ & $\begin{array}{c}4000 \\
0.309\end{array}$ & $\begin{array}{c}4000 \\
0.313\end{array}$ & $\begin{array}{c}4000 \\
0.319\end{array}$ & $\begin{array}{c}4000 \\
0.356\end{array}$ & $\begin{array}{c}3601 \\
0.318\end{array}$ & $\begin{array}{c}4000 \\
0.343\end{array}$ & $\begin{array}{c}4000 \\
0.343\end{array}$ \\
\hline
\end{tabular}

OLS with country fixed effects, monthly time dummies, and robust standard errors.

t statistic in parentheses; ${ }^{*} p<0.05,{ }^{* *} p<0.01$

date11 refers to Dec 12, 2007. Lines introduced with ECB and SNB

date12 refers to Sep 18, 2008. Lines introduced with BOJ, BOE, and Bank of Canada

date13 refers to Sep 24, 2008. Lines introduced with Australia, Sweden, Denmark, and Norway

date14 refers to Oct 28, 2008. Lines introduced with NZL, Brazil, Mexico, Korea, and Singapore

date2 refers to Oct 13, 2008. Unlimited swaps introduced with ECB, BOE, BOJ, and SNB 